\title{
Cladistics
}

Cladistics (2012) 1-22

$10.1111 / \bar{j} .1096-0031.2012 .00405 . x$

\section{Revival of Palaeoptera-head characters support a monophyletic origin of Odonata and Ephemeroptera (Insecta)}

\author{
Alexander Blanke ${ }^{\mathrm{a}, *}$, Benjamin Wipfler ${ }^{\mathrm{b}}$, Harald Letsch ${ }^{\mathrm{c}}$, Markus Koch ${ }^{\mathrm{d}}$, \\ Felix Beckmann ${ }^{\mathrm{e}}$, Rolf Beutel ${ }^{\mathrm{b}}$ and Bernhard Misof ${ }^{\mathrm{a}}$ \\ ${ }^{a}$ Forschungsmuseum Alexander Koenig, Adenauerallee 160, 53113 Bonn, Germany; ${ }^{b}$ Entomology Group, Institut für Spezielle Zoologie und \\ Evolutionsbiologie, Friedrich-Schiller-Universität Jena, Erbertstraße 1, 07743 Jena, Germany; ${ }^{c}$ Department für Tropenökologie und Biodiversität \\ der Tiere, Universität Wien, Rennweg 14, A-1030 Vienna, Austria; ${ }^{d}$ Institute of Evolutionary Biology and Animal Ecology, University of Bonn, \\ An der Immenburg 1, 53121 Bonn, Germany; ${ }^{e}$ Institute of Materials Research, Helmholtz-Zentrum Geesthacht, Max-Planck-Str. 1,21502 \\ Geesthacht, Germany
}

Accepted 30 March 2012

\begin{abstract}
The earliest branching event in winged insects, one of the core problems regarding early insect evolution, was addressed using characters of the head. The head is arguably one of the most complex body regions in insects and the phylogenetic information content of its features has been demonstrated. In contrast, the wings and other body parts related to the flight apparatus and sperm transmission are not useful in the context of this problem, as the outgroups (silverfish and bristletails) are wingless and transmit spermatophores externally. Therefore, they show profound differences in the organization of the postcephalic body, and assessment of homology and subsequent phylogenetic analysis of features of these body regions is extremely difficult. The core of this study is the investigation of head structures of representatives of the major clades of dragonflies. A detailed description of the head of Lestes virens is presented and was used as a starting point for the compilation of a character set and a character state matrix for the entire Dicondylia (winged insects + silverfish), with a main focus on the placement of dragonflies and consequently the basal branching event within winged insects. Our results indicate a sister-group relationship between a clade Palaeoptera (dragonflies + mayflies) and the megadiverse monophyletic lineage Neoptera. We show that despite considerable structural similarity between the odonate and neopteran mandible, the muscle equipment in dragonflies is more plesiomorphic with respect to Dicondylia than previously known. Odonata and Ephemeroptera also share presumably derived features of the antenna, maxilla, and labial musculature. Parsimony analyses of the head data unambiguously support a clade Palaeoptera.
\end{abstract}

(C) The Willi Hennig Society 2012.

Whole tagmata have been successfully used to infer insect phylogenies (Beutel et al., 2010; Friedrich and Beutel, 2010). Generally, head, thorax and abdomen each provide a rich set of phylogenetically informative characters. However, in the case of the earliest branching events within winged insects (Pterygota), i.e. the relationships between dragonflies (Odonata), mayflies (Ephemeroptera), and all remaining winged insects (Neoptera), fundamental problems become apparent. Evolution of the flight apparatus caused a drastic

\footnotetext{
*Corresponding author: E-mail address: blanke@uni-bonn.de
}

redesign of the thoracic morphology. This makes a reliable homologization of several thoracic elements between wingless (apterygote) and winged (pterygote) lineages highly problematic (Beutel and Gorb, 2006). In a phylogenetic context, the definition of characters (primary homology hypotheses) is often difficult or impossible. This impedes a formal phylogenetic evaluation of thoracic features using the outgroup criterion. A similar dilemma exists with characters related to the reproductive system due to the drastically different mode of sperm transfer, i.e. externally deposited spermatophores versus internal fertilization using an intromittent organ (Boudreaux, 1979; Witte and Doring, 
1999). Moreover, homologizing reproductive elements between some neopteran taxa, i.e. within the same functional assemblage showing direct sperm transfer, is problematic (Klass, 2009). Again, this impedes the homologization between wingless and winged insect lineages and character state polarization. Nonetheless, these character systems have been used for decades to reconstruct the basal splitting in winged insects (Boudreaux, 1979; Kristensen, 1975, 1998; Kukalová-Peck, 1997, 2008; Soldán, 2003).

Basically, our approach is to infer the general evolutionary trends of these problematic organ systems indirectly by choosing another body region. The head is suitable as it is not directly affected by the evolution of the flight apparatus or the modified sperm transfer. The homologization of head structures between bristletails (Archaeognatha), silverfish (Zygentoma), and the winged lineages of insects (Pterygota) is straightforward and unproblematic, with the possible exception of the hypopharyngeal complex. It was demonstrated that the homology of head muscles between primarily apterygote and winged groups of insects can be assessed without particular problems (Denis and Bitsch, 1973; Matsuda, 1965). Numerous detailed morphological investigations have been carried out concerning Ephemeroptera and Odonata (Mathur and Mathur, 1961; Short, 1955; Staniczek, 2000, 2001; Strenger, 1952, 1954, 1970, 1975), but with limited taxon sampling, randomly chosen taxa in different studies, and without a formal, numerical evaluation. Consequently, in this comparative study of head structures we attempted not only to acquire detailed data for the hitherto under-represented taxa dragonflies (Odonata) and mayflies (Ephemeroptera), but also a broad spectrum of representatives of other insect lineages.

The relationships of the three basal winged lineages (Odonata, Ephemeroptera, and Neoptera) is one of the major unsolved problems in entomology (Klass, 2007; Kristensen, 1991). All three possible solutions have been proposed and are still under discussion. A sister-group relationship between Ephemeroptera and Odonata (Palaeoptera hypothesis) has been advocated based on characters of the wing venation and articulation as well as maxillary configuration (Bechly et al., 2001; Brauckmann and Zessin, 1989; Haas and Kukalová-Peck, 2001; Hennig, 1969; Hovmöller et al., 2002; Kukalová-Peck, 1997, 2008; Soldán, 2003; Wheeler et al., 2001; Willkommen and Hörnschemeyer, 2007).

A sister-group relationship between Ephemeroptera and Neoptera (Chiastomyaria hypothesis) is suggested by the mode of direct sperm transfer, indirect flight musculature, and molecular analyses based on rRNA genes (Boudreaux, 1979; Kjer, 2004; Mallatt and Giribet, 2006; Matsuda, 1970; Simon et al., 2009). A sistergroup relationship between Odonata and Neoptera (Metapterygota hypothesis) is hypothesized, for example, based on features of the mandibles and the respiratory system, and also by molecular data (Beutel and Gorb, 2006; Kristensen, 1991; Ogden and Whiting, 2003; Pass et al., 2006; Staniczek, 2000, 2001; Terry and Whiting, 2005; Wheeler et al., 2001). Finally, most recent studies based on primary sequence data of complete mitochondrial genomes (Lin et al., 2010; Zhang et al., 2010) supported a clade Ephemeroptera + Plecoptera as sister group to all remaining pterygotes, thus challenging the monophyly of Neoptera.

Issues concerning the relationships between Ephemeroptera, Odonata, and Neoptera have often been addressed as the "Palaeoptera problem" (Hovmöller et al., 2002; Ogden and Whiting, 2003; Whitfield and Kjer, 2008), which implies a problematic grouping of Ephemeroptera + Odonata. The appearance of Ephemeroptera, Odonata, and the neopteran orders in a geologically relatively short time span - probably some time during or after the Devonian (Engel and Grimaldi, 2004; Gaunt and Miles, 2002; Grimaldi and Engel, 2005) - has been followed by a long period in which these lineages have evolved separately. This specific evolutionary pattern, previously described as an "ancient rapid radiation", has been assumed to necessarily hamper phylogenetic reconstructions (Kjer et al., 2006; Rokas and Carroll, 2006; Whitfield and Kjer, 2008; Whitfield and Lockhart, 2007) as all evolutionary changes useful to display the branching patterns of Ephemeroptera, Odonata, and Neoptera must have been accumulated in the short branches linking these lineages, whereas subsequent changes occurring in the branches leading to the terminal groups do not provide information about their relationships.

To contribute to a resolution of this persistent problem, we studied the complex head anatomy of representatives of all major insect lineages, including a bristletail, a silverfish, eight species of mayflies, seven species of dragonflies, and 30 representatives of all major neopteran lineages. Eighteen taxa are represented by original data.

In terms of available morphological data dragonflies are an unusual case. Whereas the thoracic (Pfau, 1986, 1991; Willkommen, 2009; Willkommen and Hörnschemeyer, 2007) and abdominal morphology (Klass, 2008; Matushkina, 2008a,b; Pfau, 2002, 2005; Whedon, 1918) have been intensively studied, the head has been largely neglected. The latest treatments of dragonfly head anatomy (Asahina, 1954; Hakim, 1964; Mathur, 1962; Mathur and Mathur, 1961; Short, 1955; Strenger, 1952) were insufficient for a clarification of the systematic position of the order (Wipfler et al., 2011). Consequently, our primary aim is a detailed examination and documentation of dragonfly head structures. The data obtained, combined with information from specific morphological studies and comparative investigations, form the basis of a new assessment of the systematic position of dragonflies, which is crucial for 
our understanding of the early evolution of the most successful group of organisms.

\section{Material and methods}

Anatomy was investigated using synchrotron microcomputed tomography (SR-microCT) (Betz et al., 2007). Prior to scanning, samples were critical-point dried (Model E4850, BioRad) and mounted on specimen holders. Except for Siphlonurus lacustris and Thermobia domestica, all specimens were scanned at the beamline BW2/DORIS III at the Deutsches Elektronen-Synchrotron (DESY, Hamburg, Germany) using a monochromatic X-ray beam at $8 \mathrm{keV}$ photon energy. The tomography station operated by Helmholtz-Zentrum Geesthacht (HZG, Geesthacht, Germany) is optimized for performing high-density resolution microtomography (Beckmann et al., 2008). T. domestica was scanned at beamline TOMCAT at the Swiss Light Source, Paul Scherrer Institut (PSI, Villigen, Switzerland) and S. lacustris at the high-resolution computed tomography scanner $\mathrm{v}$ |tome $\mid \times s$ (GE phoenix|x-ray, Steinmann-Institut, Bonn, Germany) (Table 1). Subsequent segmentation and rendering was accomplished with Reconstruct (Fiala, 2005) and Blender (http://www.blender.org). Both software packages are distributed under the GPL licence. Final tables were edited with GIMP (GPL), Adobe Photoshop $^{\circledR}$, and Adobe Illustrator ${ }^{\circledR}$ (Adobe Corp., San Jose, CA).

Readers not familiar with insect head morphology are encouraged to check the supporting information for this paper (Data S4). A three-dimensional model of the head of Lestes virens is presented in this file, which facilitates the identification of internal structures. The underlying program "Blender" can be downloaded free of charge under the GPL licence from http://www.blender.org. For instructions, http://wiki.blender.org/index.php/ Doc:Manual can be used.
For scanning electron microscopy (SEM), specimens were transferred in a series of steps into $100 \%$ ethanol, critical-point dried (Model E4850; BioRad, Hercules, CA), and sputter coated (Model; Hummer VII, Anatech, Union City, CA). Microscopy was performed on a Hitachi S-2460N using a new type of rotatable sample holder (Pohl, 2010). Additional information for taxon sampling was obtained from the literature (Table 2).

We consistently use the term "suture" for ecdysial cleavage lines (DuPorte, 1946, 1957; Snodgrass, 1947) and "ridge" for any cuticular strengthening lines or ridges (Snodgrass, 1935, 1947; Strenger, 1952). We avoid the term "sulcus" completely because this refers to a fissure between bones. Morphological definitions and structure designations follow Seifert (1995).

Literature sources were partly used for character 19 (Staniczek, 2000) and for characters 35, 36, 37, 38, 39, 40, 45, and 46 (Pass et al., 2006; Pass, 2000).

\section{Phylogenetic analyses}

Parsimony analyses of the morphological character set and Bremer as well as bootstrap support calculations were carried out with TNT (Goloboff et al., 2008) using 1000 heuristic searches starting with random addition of taxa (TBR branch swapping). All characters were equally weighted and unordered. Only unambiguous changes were mapped on the tree. Optimizations were analysed with WinClada ver. 1.00.08 (Nixon, 2002). To explore evolutionary implications of alternative hypotheses we used constrained tree reconstruction (CTR) executing the "move branch mode" in WinClada. These CTRs were Metapterygota [Ephemeroptera (Odonata + Neoptera)], Chiastomyaria [Odonata (Ephemeroptera + Neoptera)], and paraphyletic Neoptera [Odonata + ((Ephemeroptera + Plecoptera) + other Neoptera))] (Lin et al., 2010). The following abbreviations are used for these hypotheses: Palaeoptera, PP; Metapterygota, MP; Chiastomyaria, CM; paraphyletic Neoptera, PN.

Table 1

Scanning parameters used for the investigated taxa; for the scans at BW2 (DESY) and TOMCAT (SLS at PSI) monochromatic X-rays are used

\begin{tabular}{|c|c|c|c|c|c|}
\hline \multirow[b]{2}{*}{ Taxon } & \multirow[b]{2}{*}{ Species } & \multirow[b]{2}{*}{ Beamline } & \multicolumn{3}{|c|}{ MicroCT specifications } \\
\hline & & & Energy (keV) & Magnification & Pixel size $(\mu \mathrm{m})$ \\
\hline Archaeognatha & Machilis sp. & $\begin{array}{l}\text { BW2 (DESY) and } \\
\text { TOMCAT (SLS) }\end{array}$ & 8 & 2.7 and 10 & 5.01 and 10 \\
\hline Zygentoma & Thermobia domestica & TOMCAT (SLS) & 8.5 & 10 & 0.74 \\
\hline \multirow[t]{3}{*}{ Ephemeroptera } & Siphlonurus lacustris & $\mathrm{v} \mid$ tome $\mid \mathrm{x}$ (Steinmann) & 20.5 & 4 & 7.87 \\
\hline & Ephemera danica & BW2 (DESY) & 8 & 2.9 & 6.06 \\
\hline & Heptagenia sulphurea & BW2 (DESY) & 8 & 2.9 & 6.06 \\
\hline \multirow[t]{3}{*}{ Odonata } & Lestes virens & BW2 (DESY) & 8 & 3.4 & 4.69 \\
\hline & Epiophlebia superstes & $\begin{array}{l}\text { BW2 (DESY) and } \\
\text { TOMCAT (SLS) }\end{array}$ & 8 and 10 & 1.9 and 2 & 9.46 and 3.7 \\
\hline & Onychogomphus forcipatus & BW2 (DESY) & 8 & 1.9 & 9.46 \\
\hline Plecoptera & Perla marginata & BW2 (DESY) & 8 & 1.9 & 9.46 \\
\hline
\end{tabular}


Table 2

Taxa used in the morphological data matrix and the corresponding data source; original data from Friedemann et al. (2012) and Wipfler et al. (2011, 2012) were available to the authors

\begin{tabular}{|c|c|c|c|}
\hline Higher ranking taxon & Species & & Data source \\
\hline Archaeognatha & Machilis germanica Janetschek 1953 & & $\begin{array}{l}\text { SR-microCT (HZG, DESY and } \\
\text { SLS at PSI) }\end{array}$ \\
\hline \multirow[t]{2}{*}{ Zygentoma } & Thermobia domestica (Packard, 1837) & & SR-microCT (SLS at PSI) \\
\hline & Thermobia domestica (Packard, 1837) & & Chaudonneret $(1948,1950)$ \\
\hline \multirow[t]{4}{*}{ Ephemeroptera } & Siphlonurus lacustris (Eaton 1870) & (larva) & microCT (vtomex at Steinmann) \\
\hline & Oniscigaster wakefieldi McLachlan, 1873 & & Staniczek (2001) \\
\hline & Heptagenia sulphurea (Müller 1776) & (larva) & SR-microCT (HZG, DESY) \\
\hline & Ephemera danica (Müller, 1764) & (larva) & SR-microCT (HZG, DESY) \\
\hline \multirow[t]{8}{*}{ Odonata } & Lestes virens (Charpentier, 1825) & & SR-microCT (HZG, DESY) \\
\hline & Mnais pruinosa Selys, 1853 & & Asahina (1954) \\
\hline & Onychogomphus forcipatus (Linnaeus, 1758) & & SR-microCT (HZG, DESY) \\
\hline & Davidius nanus (Selys, 1896) & & Asahina (1954) \\
\hline & Ictinogomphus angulosus (Selys, 1854) & & Mathur and Mathur (1961) \\
\hline & Aeshna cyanea (Müller, 1764) & & Short (1955) \\
\hline & Epiophlebia superstes (Selys, 1889) & & $\begin{array}{l}\text { SR-microCT (HZG, DESY } \\
\text { and SLS at PSI) }\end{array}$ \\
\hline & Epiophlebia superstes (Selys, 1889) & & Asahina (1954) \\
\hline \multirow[t]{2}{*}{ Plecoptera } & Perla marginata (Panzer 1799) & (larva) & SR-microCT (HZG, DESY) \\
\hline & Nemoura cinerea (Retzius, 1783) & & Moulins (1968) \\
\hline \multirow[t]{2}{*}{ Grylloblattodea } & Grylloblatta campodeiformis Walker, 1914 & & Walker (1931) \\
\hline & Galloisiana yuasai Asahina, 1959 & & $\begin{array}{l}\text { Wipfler et al. (2011) (SR-microCT } \\
\text { at HZG, DESY) }\end{array}$ \\
\hline \multirow[t]{2}{*}{ Mantophasmatodea } & Karoophasma sp. & & Baum et al. (2007) \\
\hline & Austrophasma sp. & & Wipfler et al. (2011) (BESSY) \\
\hline Blattodea & Periplaneta americana Linnaeus, 1758 & & Wipfler et al. (2011) (BESSY) \\
\hline Mantodea & Hymenopus coronatus (Olivier 1792) & & Wipfler et al. (2012) \\
\hline \multirow[t]{5}{*}{ Phasmatodea } & Timema christinae Vickery, 1993 & & Tilgner et al. (1999) \\
\hline & Agathemera crassa (Blanchard, 1851) & & Wipfler et al. (2011) (BESSY) \\
\hline & Megacrania batesii Kriby, 1896 & & Friedemann et al. (2012) (BESSY) \\
\hline & Phyllium siccidifolium (Linnaeus, 1758) & & Friedemann et al. (2012) (BESSY) \\
\hline & Sipyloidea sipylus (Westwood, 1859) & & Friedemann et al. (2012) (BESSY) \\
\hline Embioptera & Embia ramburi Rimsky-Korsakow, 1906 & & Rähle (1970) \\
\hline Dermaptera & Labidura riparia (Pallas, 1773$)$ & & Kadam (1961) \\
\hline Orthoptera & Locusta migratoria (Linnaeus, 1758) & & Albrecht (1953) \\
\hline Zoraptera & Zorotypus hubbardi Caudell, 1918 & & Beutel \& Weide (2005) \\
\hline Psocoptera & Stenopsocus stigmaticus (Imhoff \& Labram, 1846) & & Badonnel (1934) \\
\hline Hymenoptera & Macroxyela sp. & & Beutel \& Vilhelmsen (2007) \\
\hline
\end{tabular}

In addition to the parsimony approach, we also conducted maximum-likelihood (ML) and Bayesian inference (BI) analyses. To model morphological characters by these methods, the Mk (for Markov with $k$-states) model has been introduced by Lewis (2001). The Mk model is a generalization of the Jukes-Cantor model (Jukes et al., 1969), assuming all states have the same frequency and all transitions between different states occur at the same rate (Allman et al., 2009; Lewis, 2001). In the present study, ML analyses were conducted with RAxML ver. 7.2.6 (Ott et al., 2007; Stamatakis, 2006; Stamatakis et al., 2005). The Mkv model was applied, with all model parameters estimated from the data, and rate heterogeneity across characters was considered by applying the gammamodel of Yang (1994) with four discrete categories. Node support was estimated with 1000 Bootstrap replicates.
BI was conducted using MrBayes ver. 3.2 (Huelsenbeck and Bollback, 2001; Ronquist and Huelsenbeck, 2003). Again, the Mk model was applied, with among-character rate variation modelled with gammadistributed rates across characters with four discrete rate categories. Priors were set adopting the default settings of MrBayes. Two parallel analyses were run with random starting trees and four Metropolis coupled Markov chains for 1000000 generations. Every 100th generation was sampled to yield a posterior probability distribution of 10000 trees. After discarding the first 1000 trees of each run as burn-in, a $50 \%$ majority rule consensus tree was calculated from the concatenated sample trees of both runs.

The matrix is based on those presented in Wipfler et al. (2011) and Friedemann et al. (2012) (Data S2 and S3), extended by 38 new characters. Eighteen characters of Wipfler et al. (2011) were excluded from our analysis 
as their homologization between taxa is unclear (Data S3). In the descriptions and tree figures, species are referred to by generic names only.

\section{Results}

\section{Head morphology of Lestes virens}

The orthognathous head (mouthparts ventrally oriented) is strongly sclerotized and the surface is covered with a moderately dense vestiture of setae (Fig. 1a,b). It is more than twice as wide as long. Approximately $40 \%$ of its width is occupied by the large, dome-shaped, laterally positioned compound eyes. They are placed on sockets formed by the enlarged postgenae, thus facing slightly forward. Anteriorly the eyes are approximately twice as broad as posteriorly (Fig. 2a). Each eye comprises more than 20000 ommatidia and is internally enclosed by a strongly developed, wide circumocular ridge (cor). Mesally, the compound eyes do not touch each other.

The short coronal (cs) and frontal sutures (fs) or ecdysial cleavage lines are visible as an inverted " $Y$ " on the dorsal head region in frontal view (Figs 1a and 2a). Three ocelli (moc, loc) are present between these sutures close to their junction point. The frontal sutures do not reach the circumantennal ridges (car). The coronal suture (cs) is confluent with the transversely oriented occipital ridges (ocr), which are continuous with the internal circumocular ridges (cor). Posterior to the occipital ridge lies an occipital bar (ocb), which has a transverse orientation and is about as long as the width of the vertex (v, Fig. 2a). The occiput (oc) forms the major part of the backside of the head and bears the cephalic part of the head arresting system, which is responsible for the support and fixation of the head in different situations (see Gorb, 1999). It is composed of two vertically oriented oval fields of microtrichia on both sides of the foramen occipitale.

The postocciput around the posterior head opening or foramen occipitale is small and partly separated from the other head regions by an incomplete postoccipital ridge, which forms an incomplete arch above the foramen occipitale. It is dorsolaterally interrupted on both sides, thus represented by a dorsal nearly horizontal part and two lateral vertical parts. The foramen is roughly oval and narrow. The narrowed neck region and cervical membrane result in a high mobility of the head in the roll, pitch, and yaw planes.

The oval antennal foramina are surrounded by complete circumantennal ridges (car) and interconnect by a distinct interantennal ridge (iar, Fig. 1a). An antennifer, frequently encountered in other insects, is absent. The large clypeus is divided into an ante- and postclypeus. The latter appears broader and horizontally oriented in lateral view, whereas the anteclypeus has a vertical orientation (Fig. 2c). The anteclypeus is not membranous, but as heavily sclerotized as the postclypeus (same thickness and material density in the microCT data). Despite this, the anteclypeus is "softer" than the stiff postclypeus and therefore clearly distinguishable from the latter (see also Asahina, 1954). The frons (fr) is separated from the postclypeus (pcl) by a strong, transverse epistomal ridge (er, Fig. 1a). The interantennal ridge (iar) subdivides the frons into an anterior bead-like part and a posterior flat and more vertically oriented region in lateral view (Fig. 2c). In frontal view the entire clypeus has a trapezoid shape (Fig. 1a). The anterior tentorial pits (atp) are continuous with the pleurostomal ridge, which is curved posteriorly and confluent with the hypostomal ridge. The subgenal ridge (= hypostomal + pleurostomal ridge) is not connected with the circumoccular ridge.

The anterior elements of the cuticular head exoskeleton (anterior tentorial arms "ata", Fig. 3d) are short, massive, and twisted. Protuberances emerge at their ventral base and extend into the lumen of the mandibles. They serve as origin for mandibular muscles $(0 \mathrm{md} 6$ and 0md8, Fig. 3c). The dorsal tentorial arms (dta) also originate from the basal part of the anterior arms (Fig. 3d). They are thin, twisted, and merge with the head capsule directly dorsad of the antennal origin. The attachment points are externally recognizable as dorsal tentorial pits (dtp, Fig. 1a). All antennal muscles originate from the dorsal tentorial arms. The corpotentorium (ct, Fig. 3a) is compact and cylinder-shaped. Oesotendons are absent. The posterior tentorial arms are very short and originate from the head capsule, directly proximad of the articulation of the basal maxillary element (cardo). This is externally visible by deepened posterior tentorial pits. Short but thick apodemes, the trabeculae tentorii, originate from the ventral side of the posterior tentorial pits. They serve as attachment areas for the tentoriostipital muscles $0 \mathrm{mx} 4$ and $0 \mathrm{mx} 5$.

The anteriorly rounded, parabolic labrum partly covers the mandibles and is movably connected with the slightly rounded anterior anteclypeal margin by a membranous fold, allowing movement. It bears a vestiture of setae (Fig. 1b).

The short and thin antennae are composed of scapus, pedicellus, and three flagellomeres (Fig. 1a). Articulations between scapus, pedicellus, and flagellum are absent. The scapus is about half as long as the pedicellus but twice as wide. The first and second flagellomere are equally long. The terminal flagellomere is very short. Antennal circulatory organs (ampullary formations and antennal vessels) as well as the corresponding muscles are absent. We found no indication of any other structure which might be responsible for transportation of haemolymph into the antennae. 
(a)

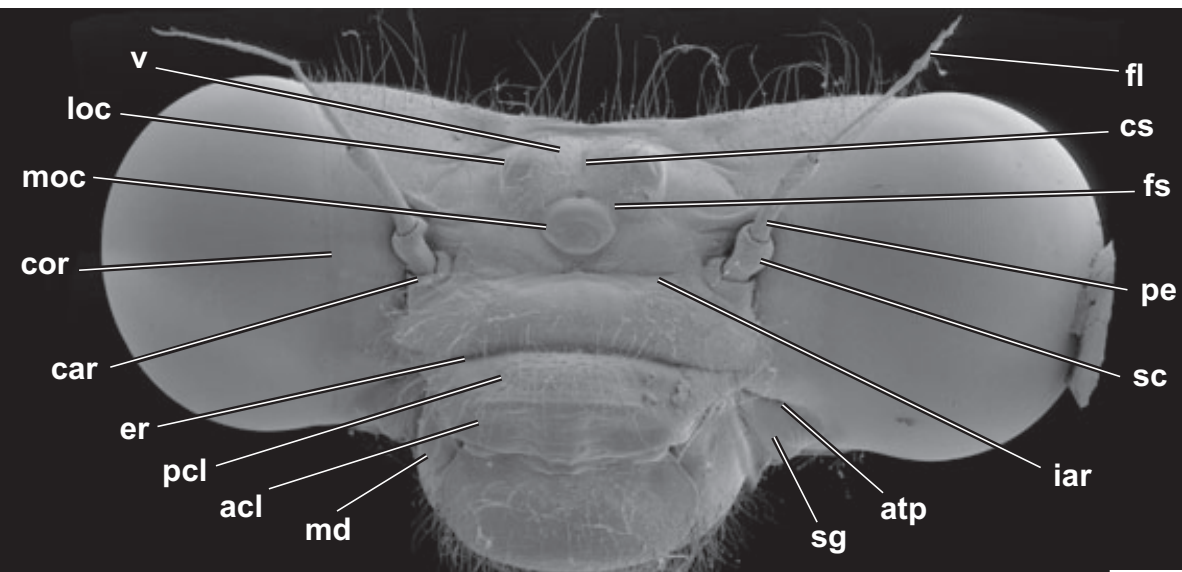

(b)

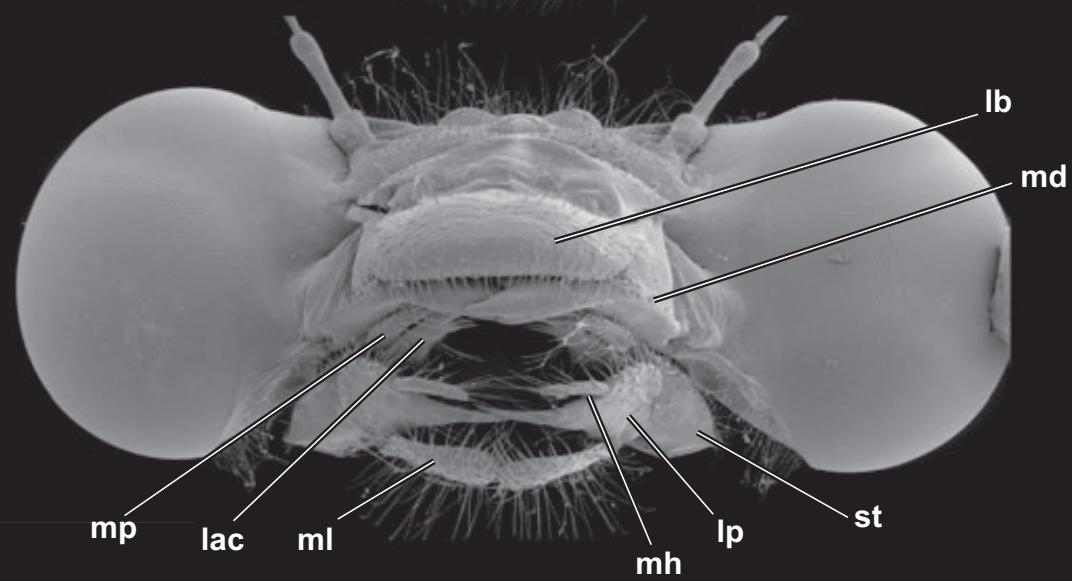

(c)
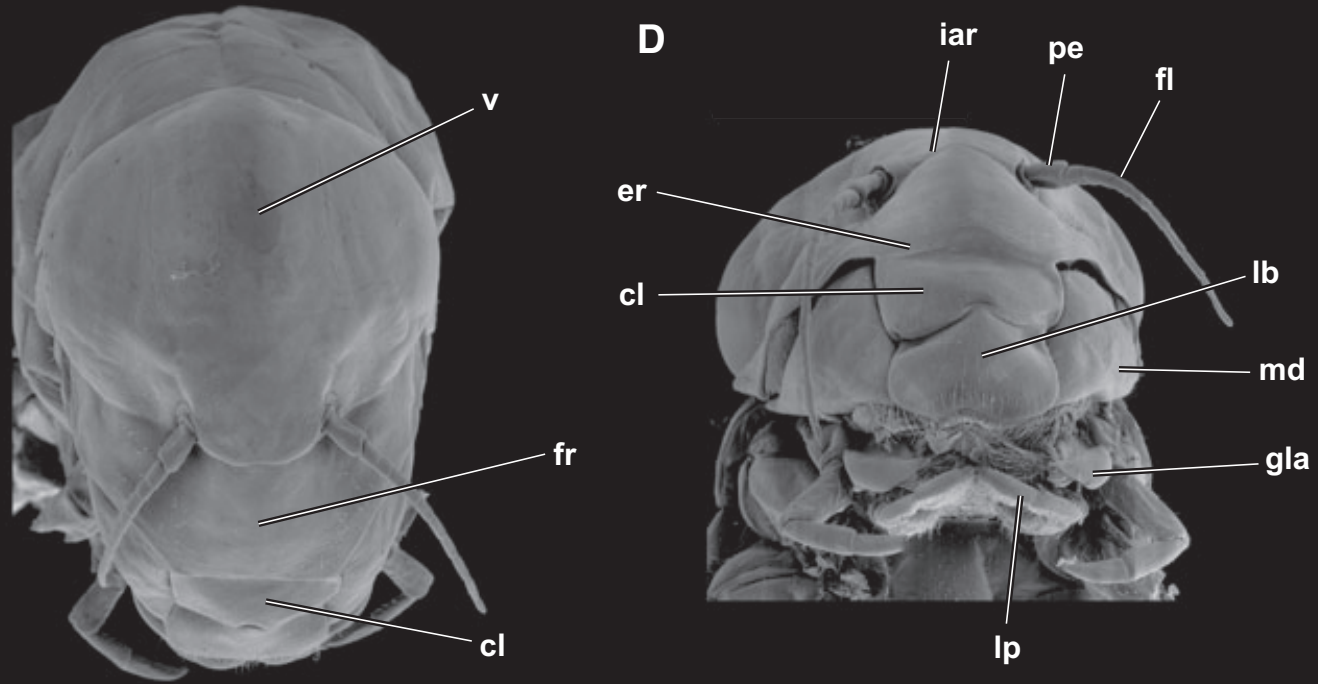

Ip

Fig. 1. SEM micrographs of Lestes virens (a, b) and Siphlonurus lacustris (c, d). (a, c) frontal view; (b, d) ventral view. Abbreviations: acl, anteclypeus; atp, anterior tentorial pit; car, circumantennal ridge; cl, clypeus; cor, circumoccular ridge; cs, coronal sulcus; er, epistomal ridge; fl, flagellum, fr, frons; fs, frontal sulcus; gla, galeolacinia; iar, interantennal ridge; lb, labrum; lp, labial palpus; md, mandible; mh, moveable hook; ml, median lobe; moc, median ocellus; mp, maxillar palpus; loc, lateral ocellus; pcl, postclypeus; pe, pedicellus; sc, scapus; sg, subgena; st, stipes; v, vertex. Scale bar $=1 \mathrm{~mm}$. 


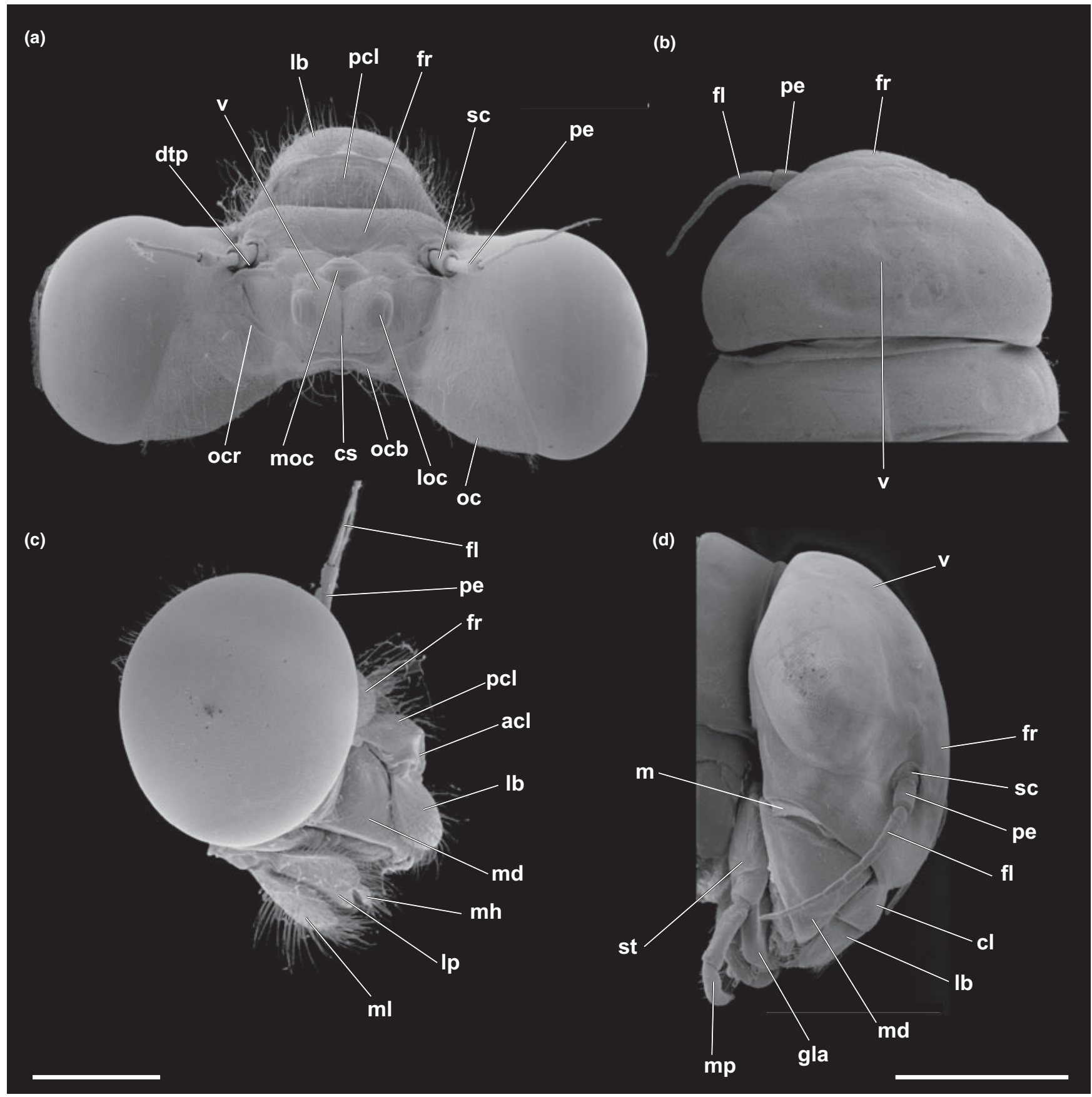

Fig. 2. SEM micrographs of Lestes virens (a, c) and Siphlonurus lacustris (b, d). (a, b) dorsal view; (d, e) lateral view. Abbreviations: acl, anteclypeus; cl, clypeus; cs, coronal sulcus; fl, flagellum; fr, frons; gla, galeolacinia; lb, labium; loc, lateral ocellus; lp, labial palpus; m, membrane; md, mandible; $\mathrm{mh}$, moveable hook; ml, median lobe; moc, median ocellus; mp, maxillar palpus; oc, occiput; ocb, occipital bar; ocr, occipital ridge; pcl, postclypeus; pe, pedicellus; sc, scapus; st, stipes; v, vertex. Scale bar $=1 \mathrm{~mm}$.

Articulation of the heavily sclerotized, slightly asymmetric mandibles is of the dicondylic (two articulations) ball-and-socket type (Fig. 4a,c). The mandible is triangular in dorsal view. At the mandible base the anterior articulation (ama, Fig. 4a) is a socket whereas the posterior articulation (pma, Fig. 4c) is a distinct knob with its respective counterparts (socket and knob) at the head. The gnathal edges of the left and right mandibles are almost symmetrical. Each mandible bears three incisivi and a z-shaped mesal edge formed by four strongly sclerotized prominences connected by sharp ridges (Fig. 4b). Additionally, the mandible bears 
(a)

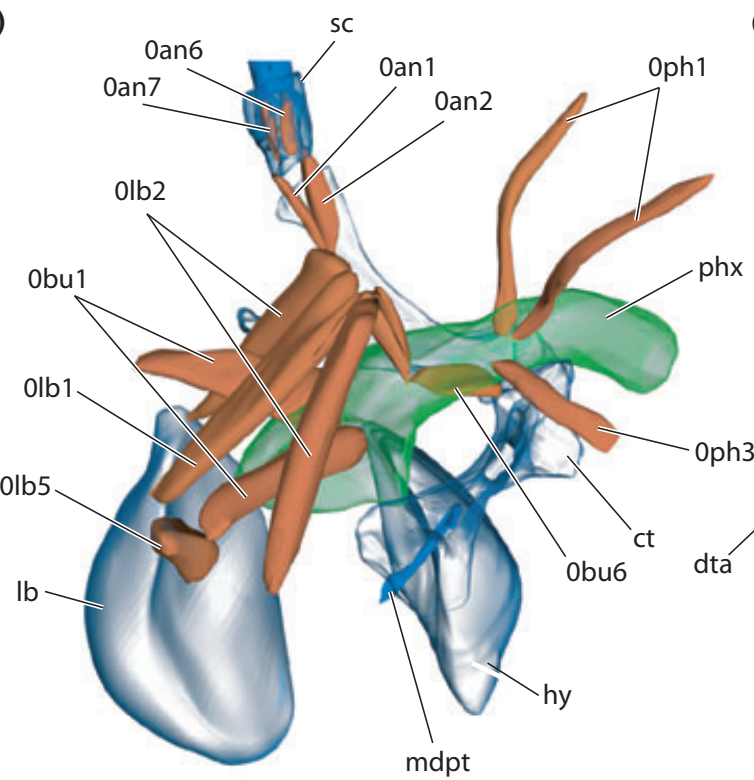

(c)
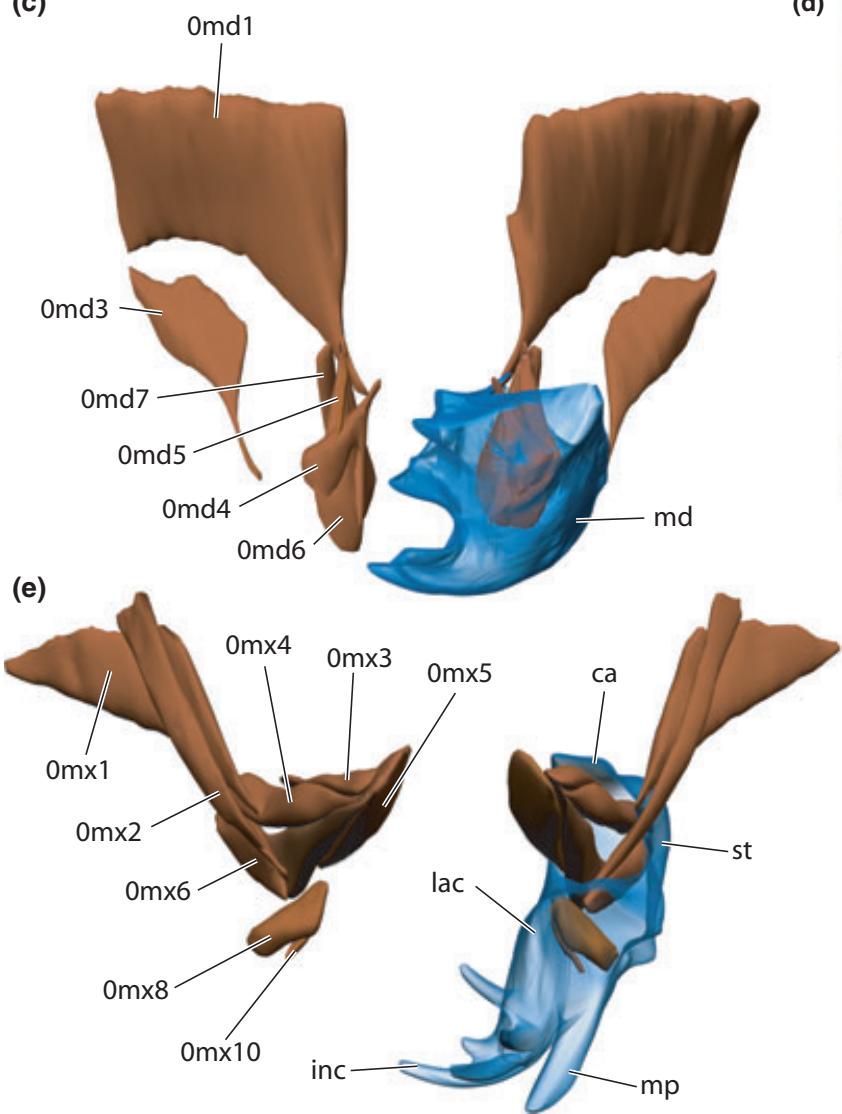

(d)
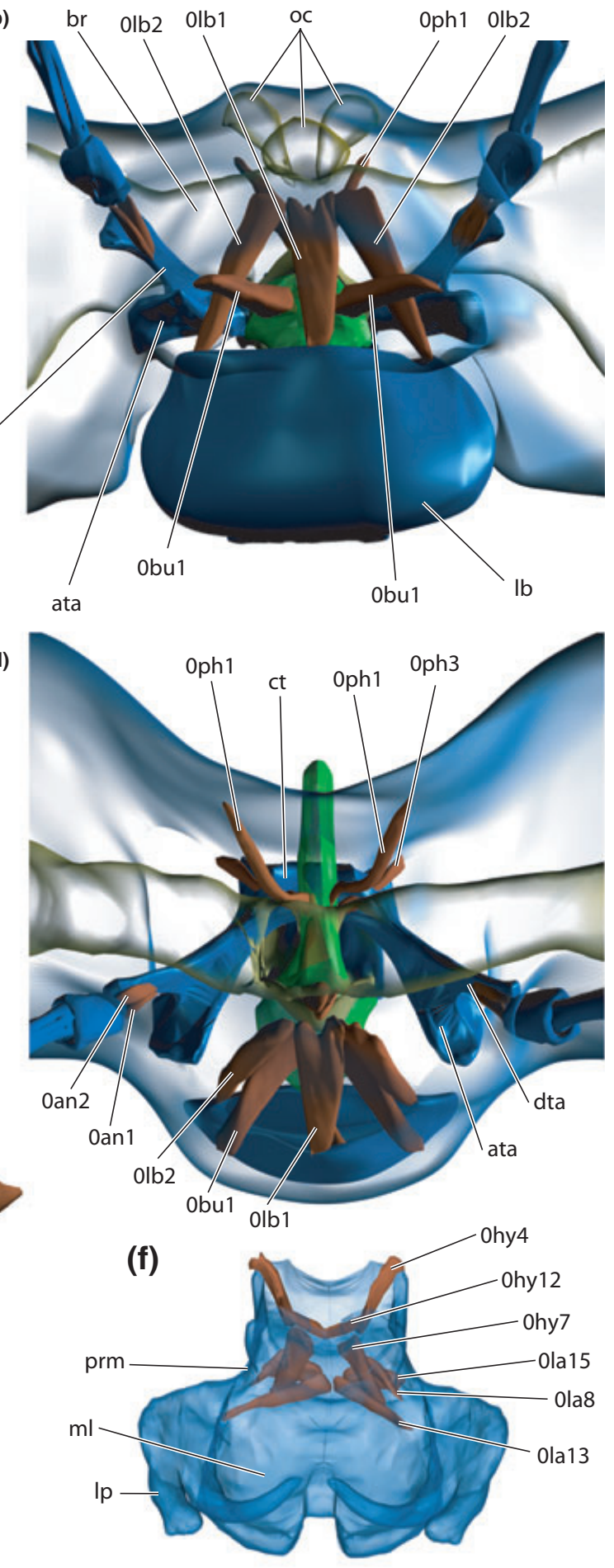

Fig. 3. Lestes virens, cephalic musculature and endoskeleton. Three-dimensional reconstructions; cuticle (blue) partly transparent. (a) head, dorsolateral view, head cuticle removed; (b) head, frontal view; (c) mandible and corresponding musculature, frontal view; (d) head, dorsal view; (e) maxillae, frontal view; (f) labium, frontal view. Muscles orange; cuticular structures blue; pharynx and oesophagus green. Abbreviations: ata, anterior tentorial arms; br, brain; ca, cardo; ct, corpotentorium; dta, dorsal tentorial arms; hy, hypopharynx; inc, incisivus; lac, lacinia; lb, labrum; lp, labial palpus; md, mandible; mdpt, mandibular process of tentorium; ml, median lobe; mp, maxillar palpus; oc, ocellus; phx, pharynx; prm, prementum; sc, scapus; st, stipes. For muscle references see Data S1. 


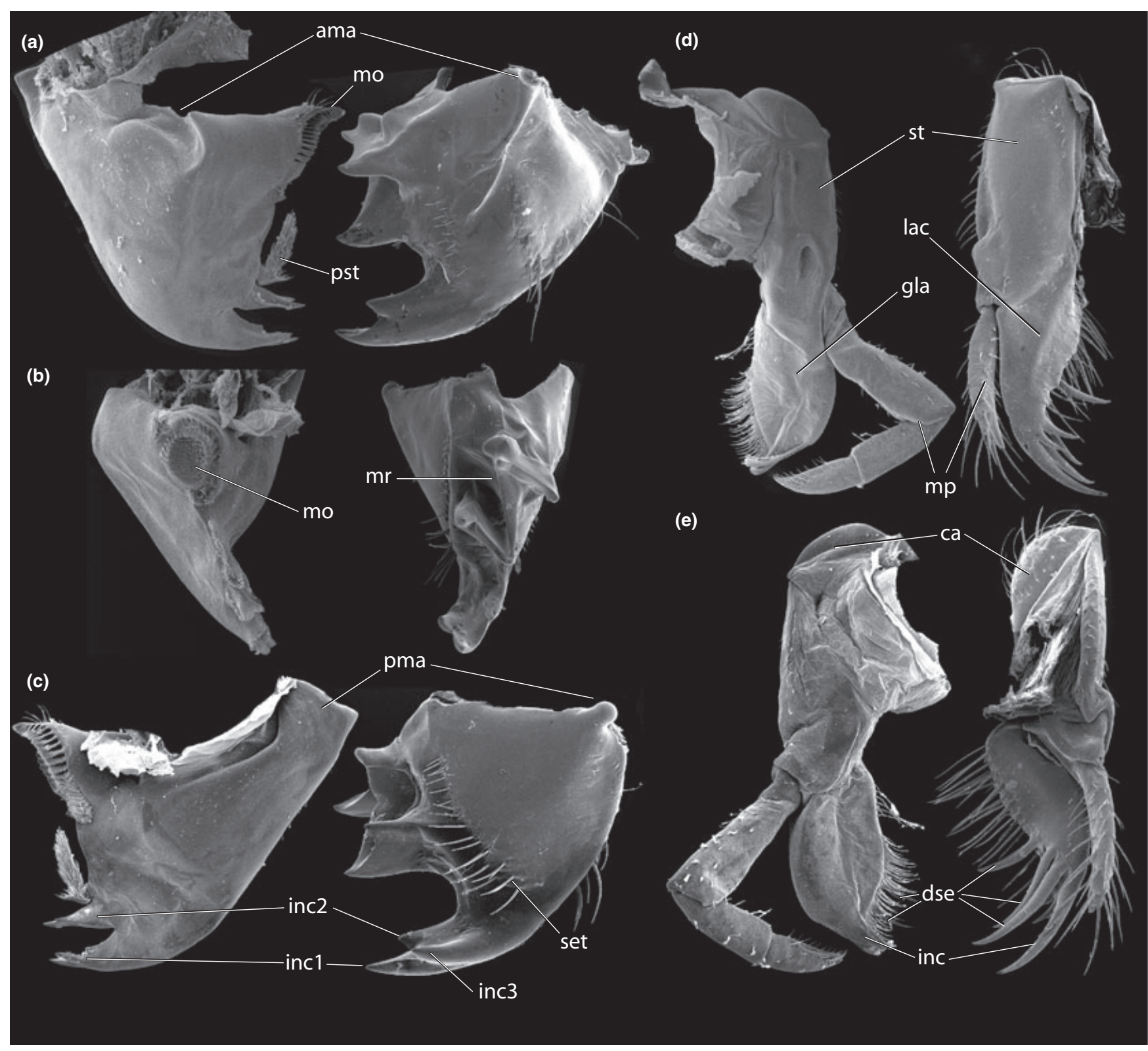

Fig. 4. Mandible and maxilla of Lestes virens and Siphlonurus lacustris in direct comparison. Left mouthpart always from S. lacustris, right mouthpart always from L. virens. SEM micrographs. (a) mandibles frontal view; (b) mandibles lateral view; (c) mandibles posterior view; (d) maxillae ventral view; (e) maxillae dorsal view. Abbreviations: ama, anterior mandibular articulation; ca, cardo; dse, dentisetae; eh, end hook of labial palp; gl, glossa; gla galeolacinia; hy, hypopharynx; inc, incisivus; inc1, frist incisivus of mandible; inc2, second incisivus of mandible; inc3, third incisivus of mandible; lac, lacinia; lp, labial palp; mh, moveable hook of labial palp; ml, median lobe; mo, mola; mp, maxillar palp; mr, mesal ridge; pma, posterior mandibular articulation; pgl, paraglossa; prm, prementum; pst, prostheca; set, setae; sli, superlinguae; st, stipes. Mouthparts not to scale among each other.

several rows of setae on the anterior and posterior surfaces.

The maxillae are long and slender. The undivided triangular cardo is clearly separated from the stipes by a groove harbouring a very narrow membrane. The stipes is a rectangular plate that is subdivided by the stipital ridge into a narrow basistipes and a much larger mediostipes (Fig. 4d,e). Its distal part bears an unseg- mented palpus covered with setae (mp, Fig. 4d). Mesally an oblique ridge separates the sickle-shaped lacinia from the stipes. The lacinia is not moveably connected to the stipes. The mesal side of the lacinia is armed with a row of long setae, two apical incisivi, and five subapical, paramesal dentisetae. A galea is absent.

The labium consists of a basal postmentum (pm) and a distal prementum (prm, Fig. 5d). The postmentum is a 


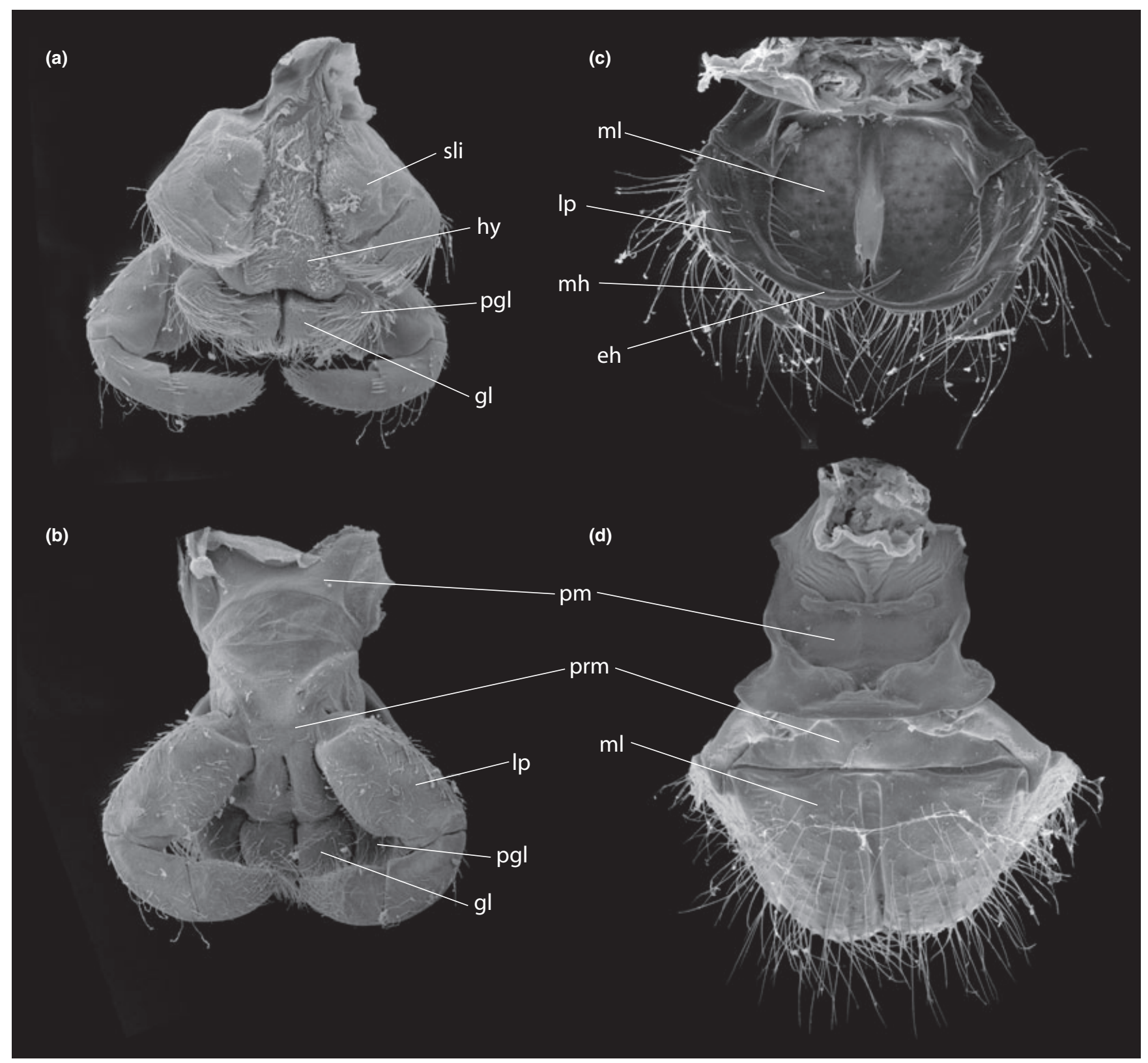

Fig. 5. Labium of Lestes virens and Siphlonurus lacustris in direct comparison. Left mouthpart always from S. lacustris, right mouthpart always from L. virens. (a, c) dorsal view; (b, d) ventral view. eh, end hook of labial palp; gl, glossa; gla, galeolacinia; hy, hypopharynx; lp, labial palp; mh, moveable hook of labial palp; ml, median lobe; pgl, paraglossa; pm, postmentum; prm, prementum; sli, superlinguae. Mouthparts not to scale among each other.

rectangular plate that is reinforced dorsally, ventrally, and laterally by heavily sclerotized bars. The short and broad prementum forms a right angle with the postmentum that is visible in lateral view. Apically it bears paired one-segmented palps and paired median lobes. The palps are flat and densely covered with setae, especially on the outer side. Apicomesally they bear a fixed subapical hook (eh, Fig. 5c). A second movable hook (mh) is present distad of this hook (Fig. 5c). The median lobes are a fusion product of glossae and paraglossa (see Discussion). Mesally the two lobes are connected by a sclerotized stripe which is approximately two-thirds as long as the lobes themselves. The ventral side of the lobes is densely covered with setae. The palps and median lobes together form a cavity for reception of the hypopharynx and maxillae.

The hypopharynx is a ventrally oriented tongue-like structure in front of the prementum. It is weakly sclerotized and bears no anterior or posterior plates. A conspicuous row of setae is present on the lateral 
surfaces. Mandibular glands are absent. The oral arm forms a rounded bar directly posterad of the anatomical mouth opening. Its serves as attachment site for $\mathrm{M}$. oralis transversalis (0hy9). The loral arm is thin and bears no linguactual tendon or apodeme.

The epipharynx is weakly sclerotized and not subdivided. It bears one lateral row of setae on the left and right side. The tormae are formed like an inverted "Y" in posterior view. They serve as attachment areas of $\mathrm{M}$. frontoepipharyngalis (0lb2).

The salivary glands are paired, mesally connected globular structures located directly ventrad of the deutocerebrum and dorsad of the salivary receptacle. The paired salivary ducts fuse before opening into the salivary receptacle, which is anteriorly continuous with an unpaired salivary channel. The channel opens into the salivarium posterad of the hypopharynx.

Pharynx and oesophagus have a wide lumen. Several dorsal, lateral, and ventral folds serve for muscle attachment.

\section{Comparison with Siphlonurus lacustris}

The following statements are restricted to features differing from descriptions in earlier studies and characters relevant for the discussion. A detailed description of ephemeropteran head morphology with comparisons between several taxa can be found in Staniczek (2000, 2001).

Head distinctly longer than wide and oval in frontal view (Fig. 1c). Compound eyes not protruding but integrated in the outline of the head capsule (Figs 1c and $2 b$ ). Coronal and frontal sutures very delicate, scarcely recognizable. Labrum (lb) parabolic (Fig. 1d). Clypeus (cl) not subdivided into ante- and postclypeus. Epistomal ridge (er) present, confluent with anterior tentorial arms and separating frons (fr) from clypeus (cl). Frons (fr) wide, subdivided by an interantennal ridge (iar), turned inwards laterally of the epistomal ridge on both sides, thus in contact with the anterior mandibular articulation complex. Infolded frontal region gradually narrowing towards posterior mandibular articulation and continuous with it (see Staniczek, 2000 for a detailed description of this structure). Ocelli sunk below cuticular and epidermal surface, not visible externally. Vertex (v) without protuberances and not clearly separated from the rest of the head capsule. Scapus very short and sunk into lumen of head capsule (Fig. 2d); pedicellus five times longer than scapus; flagellum tensegmented. Occiput without transverse bar. Head arrester system absent.

Mandible with movable prostheca (pst), lamellar mola (mo), and two incisivi (incl +2 ); mesal ridge absent (Fig. 4a-c). Posterior articulation (pma) formed by heavily sclerotized bar; anterior articulation complex (ama) with hollow concavity for reception of inflected frontal part of head. Saddle-like, ventrally bent groove originates immediately caudad the paratentorial joint (Fig. 4a, see also Staniczek, 2000, 2001). Cardo undivided; stipes divided into basi- and mediostipes; mediostipes with distinct indentation (attachment for tentoriostipital muscles) on its ventral side near the three-segmented palp (Fig. 4e). First palpomere nearly twice as long as second and third, respectively. Galea and lacinia connected by membrane along entire length and still discernible as separate structures (Fig. 4e; see Discussion). Lacinia with one apical incisivus and subapical dentisetae (Fig. 6). Labium composed of pre- and postmentum and paired glossae and paraglossae (Fig. 5a). Premental cleft absent but ventral premental apodeme present (Fig. 5b). Labial palpus threesegmented; first palpomere twice as wide and 1.5 times longer than second and third, respectively. Glossae and paraglossae separated from each other, short and globular. Hypopharynx composed of median lingua and paired lateral superlinguae (Fig. 5a). Superlinguae flat and spoon-shaped, apically with mesally directed setae. Lingua densely covered with setae.

\section{Phylogenetic analyses}

External and internal characters were scored for two outgroup and 31 ingroup taxa covering Archaeognatha, Zygentoma, Ephemeroptera, Odonata, several polyneopteran lineages, Acercaria, Zoraptera, and Endopterygota (Table 2). The matrix comprises 19 characters of

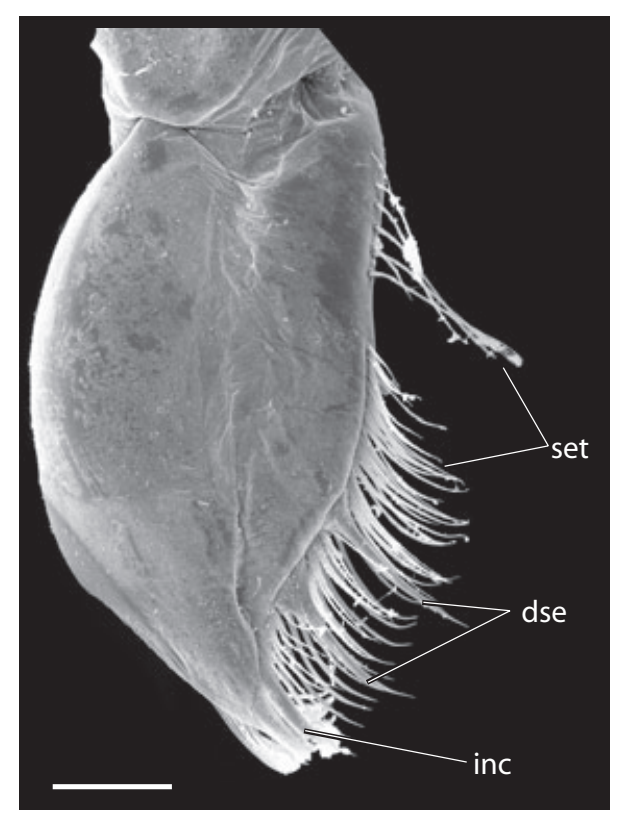

Fig. 6. The fused apical lobes of the maxilla (galea + lacinia $=$ galeolacinia) of Siphlonurus lacustris showing clearly the dentisetae and the single incisivus of the lacinia. Abbreviations: dse, dentisetae; inc, incisivus of lacinia; set, setae. Scale bar $=100 \mu \mathrm{m}$. 
the head capsule, six labral characters, 22 characters of the antennae, 13 tentorial characters, 13 mandibular characters, 17 characters of the maxillae, 33 labial characters, and 16 characters of the hypopharynx, salivarium and oesophagus (Data S2). Our morphological investigation clarifies many seemingly ambiguous

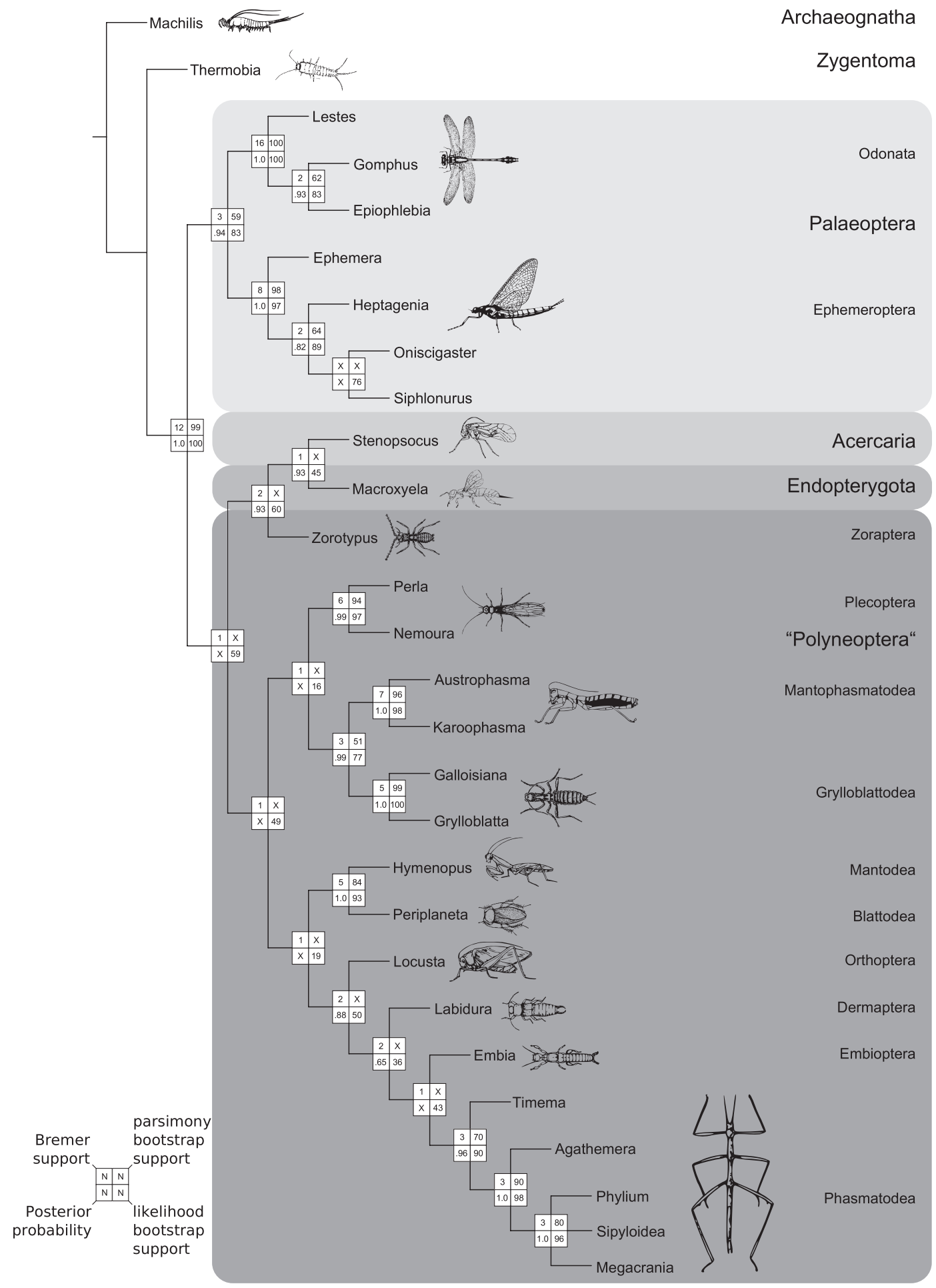

Fig. 7. Strict consensus tree derived from the TNT parsimony analysis of the morphological data matrix. Support values derived from parsimony, likelihood and Bayesian inference analyses. "X" indicates no support or a bootstrap support lower 50 and a posterior probability lower than 0.5 , respectively. 
features used in earlier studies [e.g. the presence (20) and shape of the tormae (21), dentisetae (83), glossae (96), and paraglossae $(99,100)$; see also Wipfler et al. (2011), characters 34, 35, 52, 61, 62 and 63]. In the following support values will be stated in parentheses with the following order: (Bremer support | parsimony bootstrap

| Bayes posterior probability | RaxML bootstrap value).

All analyses recover Pterygota with strong support (Fig. 7; 12|99|1.0|100). Parsimony analyses with TNT result in two equally parsimonious trees. In a strict consensus [298 steps; consistency index $(\mathrm{CI})=57$, retention index $(\mathrm{RI})=73$ ] Pterygota (winged insects) are divided into two clades: Palaeoptera (dragonflies + mayflies, 3|59|.94|83) and Neoptera (all remain- ing winged insects, $1|\mathbf{X}| \mathbf{X} \mid 59)$. ML and BI analyses produced the same branching pattern for all taxa except Labidura (Dermaptera) and Embia (Embioptera), which are sister groups in these analyses (Fig. 7). Embioptera is recovered as sister to Phasmatodea and Dermaptera as sister to Embioptera + Phasmatodea in the parsimony analysis.

The monophyly of Pterygota is strongly supported in our parsimony analyses by a series of unique autapomorphies (Fig. 8a): subdivided clypeus (15:1), absence of a postcerebral circumesophageal vessel branching off the dorsal aorta $(35: 1)$, M. tentoriobuccalis posterior (0bu6) arising at the corpotentorium (138:0), and loss of M. epistoepipharyngealis $(0 \mathrm{lb} 3,22: 1)$, M. tentorio-
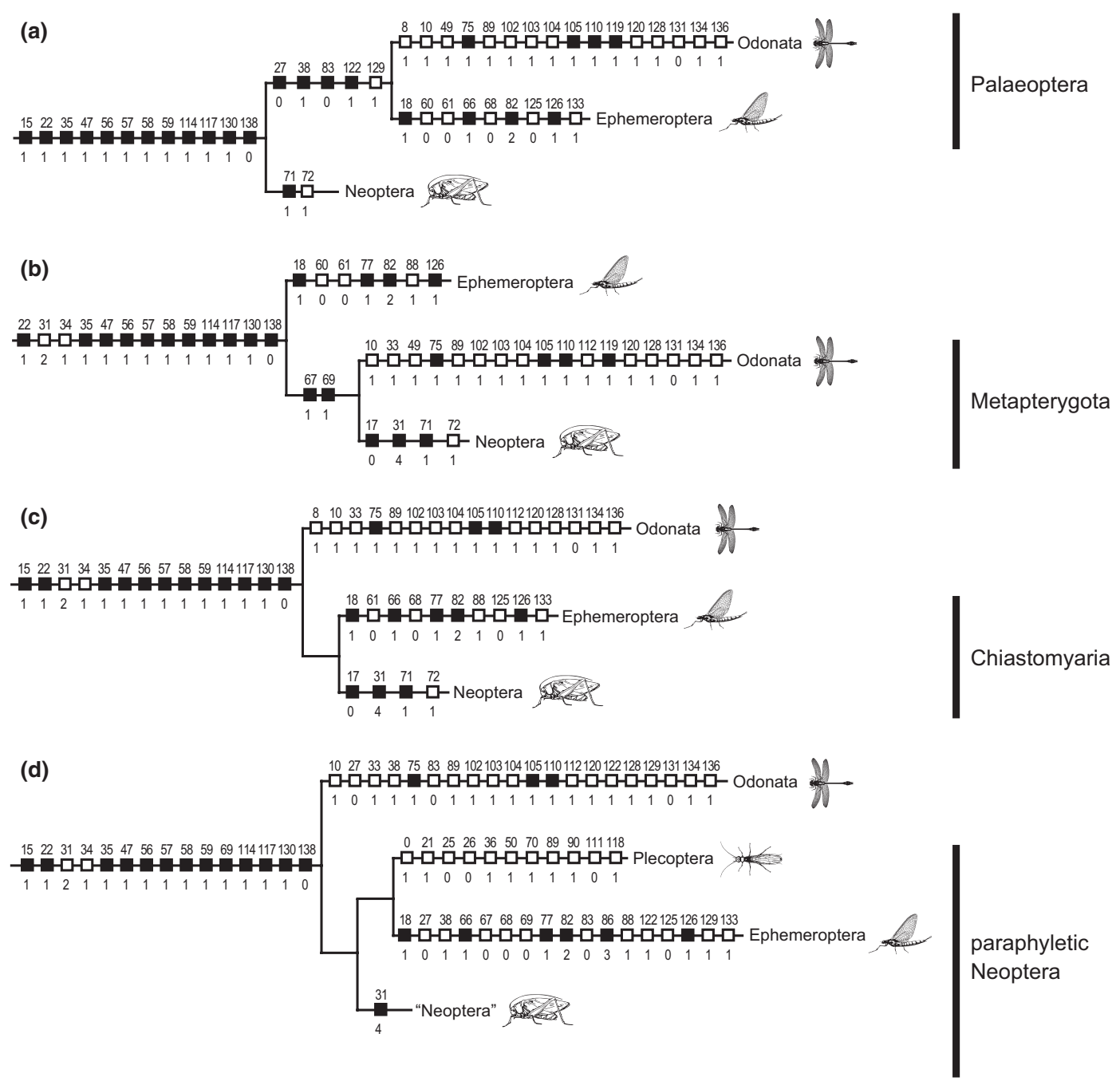

Fig. 8. Character optimizations on optimal tree resolution and CTRs of the four main hypotheses concerning basal splits of pterygotes. (a) strict consensus of the two equally parsimonious cladograms (length $=298$ steps, $\mathrm{CI}=57$, RI $=73$ ) focused on Palaeoptera received from the unconstrained analysis. B, strict consensus enforcing Metapterygota (length $=301$ steps, CI $=56$, RI $=73$ ). C, strict consensus with enforced Chiastomyaria (length $=303$ steps, $\mathrm{CI}=56, \mathrm{RI}=72)$. D, strict consensus with enforced paraphyletic Neoptera $($ Lin, 2010$)($ length $=310$ steps, $\mathrm{CI}=55, \mathrm{RI}=71)$. Non-homoplasious character changes are indicated with black squares, homoplasious characters with white squares. Trait numbers are indicated above squares, state changes below. For trait reference see Data S2 and S3. 
frontalis posterior $(0 t e 1,56: 1)$, M. posteriotentorialis (0te4, $57: 1)$, M. tentoritentorialis longis (0te5, $58: 1$ ), M. tentoritentorialis brevis $(0 t e 6,59: 1)$, M. tentorioglandularis (01a7, 114:1), M. postmentomembranus (0la9, $117: 1)$ and M. postmentoloralis (0hy6, $130: 1)$. With the exception of the clypeal subdivision $(16: 1)$ these features were robust autapomorphies of Pterygota even if the monophyly of Chiastomyaria (CM) or Metapterygota (MP) is enforced, or alternatively under a scenario with paraphyletic Neoptera (PN), all of which are retrieved as suboptimal resolutions (Fig. 8b-d). The fusion of the posterior and anterior tentoria (47:1) optimizes as another unique autapomorphy of Pterygota in our analysis but is probably homoplastic as it seems to be paralleled in Maindroniidae among zygentomans (Koch, 2003), which we have not yet included into our taxon sampling.

All insect orders sampled by more than one species are monophyletic. Odonata are monophyletic (16|100| $1.0 \mid 100)$ with Zygoptera (damselflies) as sister group of a clade Anisozygoptera + Anisoptera [= Epiprocta fide Lohmann (1996)].

Ephemeroptera were confirmed as monophyletic (8|98|1.0|97). Our analysis revealed four potential autapomorphies (Fig. 8a): non-functionality of adult mouthparts (18:1), a channel-like anterior mandibular joint (66:1), a lacinia with one incisivus $(82: 2)$, and absence of salivary glands and ductus $(126: 1)$. CTRs resulted in one additional autapomorphic feature for Ephemeroptera, the fusion of the galea and lacinia $(77: 1)$. The channel-like anterior mandibular joint (66) was not retrieved as an autapomorphy under this scenario. CTR for the CM hypothesis produced the same apomorphies as MP, and a regain of the channel-like anterior mandibular joint $(66: 1)$ as a potential autapomorphy. Under the PN hypothesis non-homoplasious characters of the CM hypothesis remained stable, but the number of homoplasious character transformations was drastically increased (Fig. 8d).

The monophyly of Neoptera is unambiguously supported by the loss of $\mathrm{M}$. tentorio-mandibularis lateralis superior $(0 \mathrm{md} 5 ; 71: 1)$. CTRs of Metapterygota and Chiastomyaria optimize a membranous anteclypeus (17:0), the origin of the antennal muscle $0 \mathrm{an} 1$ at the anterior and dorsal tentorial arms $(31: 4)$, and the absence of $0 \mathrm{md} 5(71: 1)$ as neopteran autapomorphies. If Neoptera are enforced as paraphyletic (Lin et al., 2010), the origin of the antennal muscle 0an1 at the anterior and dorsal tentorial arms $(31: 4)$ is the only potential autapomorphy of a restricted neopteran clade excluding Plecoptera.

A Palaeoptera clade is favoured by all shortest trees and is unambiguously supported by the following autapomorphies (Fig. 8a): a pedicellus longer than the scapus $(27: 0)$, the loss of antennal circulatory organs in adults (38:1), dentisetae (83:0), and the loss of labral muscle 0la14 (122: 1). Support for Palaeoptera is lower in the parsimony-based tree reconstructions (Bremer and bootstrap) and higher in model-based approaches (likelihood and Bayes).

CTR of the MP hypothesis produced a tree four steps longer (Fig. 8b). This suboptimal tree optimizes the loss of the anterolateral part of the anterior mandibular articulation (paratentorial joint; $67: 1$ ) and M. craniomandibularis externus anterior $(0 \mathrm{md} 2 ; 69: 1)$ as autapomorphies of Metapterygota.

CTR of CM resulted in a tree eight steps longer and is not supported by any head character (Fig. 8c). Simulated PN following the hypothesis of Lin (2010) (Fig. 8d) requires 12 additional steps and is also not supported by any character.

\section{Discussion}

Pterygota are also strongly supported by head characters

A single origin of winged insects (Pterygota) is generally accepted, even though it was disputed in several earlier publications (La Greca, 1980; Matsuda, 1981). However, the monophyly of Pterygota was until now poorly supported by characters of the head. The fusion of the anterior and posterior tentorial elements was the only autapomorphy mentioned in previous works (Bitsch and Bitsch, 2002; Grimaldi and Engel, 2005; Koch, 2003) but occurs at least in Mandroniidae (Zygentoma) as well.

Our investigation shows that a Pterygota clade is indeed well supported by derived features of the head (see Fig. 8 and Appendix).

\section{Evidence for palaeopteran monophyly}

A sister-group relationship between dragonflies and mayflies was not previously supported by any character of the head. Features of the mandibular articulation and muscle equipment strongly pointed towards a Metapterygota clade (Staniczek, 2000, 2001). In the present study, all lead characters potentially supporting alternative concepts (e.g. Metapterygota, Chiastomyaria) are taken into account. Nevertheless, a clade Palaeoptera (Odonata + Ephemeroptera) is consistently supported in all analyses using the entire set of characters of the head, although support levels are lower in parsimony-based tree reconstructions (Fig. 7).

A Palaeoptera clade comprising Odonata, Ephemeroptera, and some extinct Palaeozoic insect groups was first proposed by Martynow (1924) and Crampton (1924). Since then, various potential synapomorphies have been presented, including shortened antennae (Hennig, 1969), aquatic larvae (Ax, 1999), the distinct wing joint (Haas and Kukalová-Peck, 2001; Kukalová- 
Peck, 1997; Willkommen and Hörnschemeyer, 2007), and a paired penis (Bechly et al., 2001). Palaeoptera was also supported in several molecular studies (Hovmöller et al., 2002; Ishiwata et al., 2011; Kjer et al., 2006; Simon et al., 2010; Wheeler et al., 2001). Most of the morphological arguments are problematic: Palaeozoic dragonflies, mayflies, and other palaeopterans possessed multisegmented antennae (Brauckmann and Zessin, 1989; Klass, 2007; Kukalová-Peck, 1983; Soldán, 1997), which implies that the antennal shortening of mayflies and dragonflies occurred independently. Paired penises also occur in Grylloblattodea and Dermaptera (Bechly et al., 2001; Klass, 2007) and the homology in all groups concerned is problematic due to differences in ontogeny and structure (Bechly et al., 2001). Characters related to the wing or wing joint suffer from unclear character polarity as all potential outgroups are wingless (Beutel and Gorb, 2006; Whitfield and Kjer, 2008). Fossil stem group representatives of winged insects may clarify the ancestral articulation and mode of flight, but are not yet known. The argument of aquatic larvae is weak. Aquatic immature stages also occur in stoneflies (Plecoptera) and have evolved several times independently in Holometabola (Grimaldi and Engel, 2005).

We are aware that the presumptive apomorphies for Palaeoptera (Fig. 8a) need further scrutiny and critical re-evaluation using well-documented morphological characters of all body parts and/or extensive molecular data. Variations of the antennal organization frequently occur in pterygotes (Kristensen, 1991; Soldán, 1997) and generally seem to correlate with antennal size reduction. The study of more recent and extinct taxa may reveal whether an elongated pedicel is obligately correlated with antennal size reduction or an independent character synapomorphic for Ephemeroptera and Odonata. Presently available information supports the view that the distinct length ratio of the scapus and pedicellus is a unique feature of Palaeoptera and evolved only once.

The entire lack of antennal vessels in Ephemeroptera and adult Odonata was discussed by Pass (1991) and Pass et al. (2006): in early instar nymphs of Odonata a sac-like frontal sinus is present and connected to the antennal vessels. However, apparently this structure cannot be homologized with the antennal vessels of other taxa (Pass et al., 2006). As aquatic larvae originated multiple times (Grimaldi and Engel, 2005) the antennal vessels of odonate larvae may have evolved independently (Pass, 2000) and may represent another specialization and autapomorphy of this group.

The structure of the lacinia is an apparent autapomorphy of Palaeoptera. In particular, the mesally directed dentisetae are unique among winged insects. Mesally directed hyaline lamellae at similar position are usually present in Zygentoma (M. Koch pers. obs.), but these are flat, unsclerotized, strictly arranged in one row along the mesal edge, and more numerous than the dentisetae in palaeopterans. The hyaline lamellae in Zygentoma show more structural similarities to the aboral row of setae in Ephemeroptera (Staniczek, 2001) that occur at the same position on the lacinia besides dentisetae.

\section{Rejection of alternative hypotheses}

Two recent studies of the mitochondrial genome (Lin et al., 2010; Zhang et al., 2010) placed a clade Ephemeroptera + Plecoptera as sister group to all the remaining neopterans, thus rendering Neoptera paraphyletic. The authors claim that "the non-monophyly of the Neoptera is not strongly supported and needs further investigation" (Lin et al., 2010). Considering the arguments in favour of a monophyletic Neoptera and the weak support of an Ephemeroptera + Plecoptera clade, paraphyletic Neoptera appear extremely unlikely considering the data set presented here (12 additional steps in the parsimony analysis; see Fig. 8d).

Boudreaux (1979) proposed direct sperm transfer and the dominant role of indirect flight muscles as potential synapomorphies of Ephemeroptera + Neoptera (= Chiastomyaria). As pointed out above, it is not possible to determine the polarity of the latter character due to the lack of a suitable outgroup. The indirect sperm transfer of all primarily wingless hexapods is definitely not homologous to the indirect sperm transfer of Odonata (Witte and Doring, 1999). Therefore, also in this case, the polarity of the character remains ambiguous. None of the characters analysed here was a potential autapomorphy of "Chiastomyaria" and to enforce this clade eight additional steps are required in our analysis (Fig. 8c).

\section{Weakened support for Metapterygota}

The third possible combination, a clade comprising Neoptera and Odonata (= Metapterygota; Fig. 3b) (Staniczek, 2001) is favoured by most morphologists (Grimaldi and Engel, 2005; Klass, 2007; Kristensen, 1981, 1991) and was also supported in several molecular studies (Plazzi et al., 2011; Terry and Whiting, 2005; Zhang et al., 2008). Arguments in favour of this hypothesis are the suppression of the imaginal moult, additional tracheal supply of each wing and pterothoracic leg from the spiracle of the following segment, paired female gonopores, a posteriorly closed heart, loss of long terminal filaments, suppression of the hypopharyngeal superlinguae, and a series of interrelated modifications of the mandible. The Palaeoptera hypothesis supported by the characters analysed here implies that the presumptive metapterygote apomorphies have evolved independently or represent character reversals. It is conceivable that the winged subimago was lost 
independently in Odonata and Neoptera, and it was even discussed that this mode of development may have evolved several times in the winged stages (Kristensen, 1991; Kukalova-Peck, 1978). Paired female gonopores are a secondary feature of Ephemeroptera (Boudreaux, 1979). A posteriorly closed heart also occurs in Collembola and Protura, which makes the polarity assessment ambiguous (Klass, 2007; Pass et al., 2006). Superlinguae-like structures also appear in dermapterans but their homology to superlinguae in basal hexapods is highly controversial. A double tracheal supply of each wing and leg, stated as an autapomorphy for Metapterygota, is also present in some ephemeropterans (Klass, 2007; Kristensen, 1975), and the mayfly Epeorus possesses a short and slender posterior leg trachea, which is not connected to the anterior one (Chapman, 1918). Staniczek $(2000,2001)$ proposed an entire series of characters concerning the mandibular articulation, including anterior (66) and posterior ball-and-socket joints (68), a lateral shift of the anterior tentorial pit resulting in the presence of a subgenal ridge (8), and the loss of three mandibular muscles $(69,0 \mathrm{md} 2 ; 71,0 \mathrm{md} 5$; 72, 0md7). In contrast to Staniczek's findings, our reinvestigation of head structures of three odonatan representatives shows that the muscle equipment is the same as in mayflies, with the exception of M. craniomandibularis externus anterior $(70,0 \mathrm{md} 2)$. Besides this, odonatans possess an entire series of muscles, which belong to the insect groundplan (0hy4, 0hy5, 0hy12, 0la15) but are absent in Ephemeroptera. Additionally, Archaeognatha also possess a posterior mandibular ball-and-socket joint. Therefore, this character complex is ambiguous and does not support Metapterygota (or an alternative concept). The aquisition of a cylindershaped joint in the stem group of Dicondylia would require a modification to a ball-and-socket joint in Metapterygota. A cylinder-shaped posterior joint as an independent modification in Zygentoma and Ephemeroptera, respectively, would imply the presence of a ball-and-socket joint in the entire stem group of Pterygota.

\section{Mayfly head morphology partly reassessed}

Numerous studies have addressed the anatomy of the ephemeropteran head [Siphlonuridae: Schönmann (1981); Heptageniidae: Strenger (1954); Palingeniidae: Strenger (1970); Ephemeridae: Strenger (1975); Euthyplociidae: Strenger (1977)] and selected substructures (Hudson, 1951). Staniczek (2000, 2001) reviewed and homologized head structures of Ephemeroptera and reconstructed the groundplan based on an investigation of Oniscigaster wakefieldi McLachlan, 1873. Staniczek $(2000,2001)$ had to rely on larval morphology, as the mouthparts of adult mayflies are strongly reduced (Edmunds, 1988; Simm, 1914), and we followed this approach here. Generally, the comparison of characters of different life stages is problematic and a potential source of phylogenetic misinterpretations. However, the alternative, i.e. the use of adult head structures, would have been more problematic, as many characters would have been inapplicable for mayflies.

Our data corroborate that a distinct channel-like anterior mandibular joint ("Rinnengelenk" fide Staniczek, 2000; "slider" fide Kukalová-Peck, 1991) and the absence of a salivary system are defining features of ephemeropteran head organization. An orthognathous head orientation, together with three-segmented maxillary palps (muscles $0 \mathrm{mx} 13-15$ absent) and the fusion of galea and lacinia are additional features of the ephemeropteran head groundplan.

In contrast to Staniczek (2000), we consider the cuticular ridge interconnecting the anterior tentorial pits to be an epistomal ridge (er, Fig. 1). MicroCT data clearly show a strengthening of the cuticle in this region. The clypeus by definition is located ventral to the epistomal ridge (Jacobs and Seidel, 1975; Seifert, 1995; Torre-Bueno et al., 1989), which implies that Staniczek's "postclypeus" belongs to the frons. We hypothesize that the evolution of dicondyly requires the modification of other head parts as well. The formation of an epistomal ridge is one of these modifications. In agreement with Staniczek (2000, 2001), we found no indication of a subgenal ridge in Zygentoma and Ephemeroptera as is present in Odonata and Neoptera. This structure seems to be directly associated with a ball-and-socket articulation, resulting in a fixed axis of movement and increased biting forces in the transverse plane (Staniczek, 2001).

\section{A partly revised interpretation of odonate head morphology}

As already pointed out in the Introduction, the cephalic morphology of Odonata is understudied and its interpretation is subject to controversy (Asahina, 1954; Mathur and Mathur, 1961; Short, 1955; Staniczek, 2000; Strenger, 1952; Tillyard, 1917). In contrast to the present contribution (see Data S1), in all earlier studies only subsets of the musculature are described. With the exception of $\mathrm{M}$. craniomandibularis externus anterior $(0 \mathrm{md} 2)$, which is absent in Odonata and Neoptera, the mandibular muscle equipment is similar in both Ephemeroptera and Odonata (Fig. 3; Data S1 and S4).

As active predators which feed during flight, Odonata are characterized by some unique specializations such as the head arrester system (Gorb, 1999), the extremely large compound eyes with a very high number of ommatidia, and mouthparts with fused lobes $(75: 1)$, shortened palps $(86: 2,102: 1)$ and moveable labial hooks $(105: 1)$. The homology of the labial and maxillary lobes was discussed, for example, by Tillyard 
(1928) and Asahina (1954). Our data support the latter's view that the labial lobes represent a pair of fused glossae and paraglossae. In the anisozygopteran Epiophlebia superstes, the distal edge of these lobes bears two appendages on each side. We interpret these as vestiges of glossae and paraglossae based on the incomplete fusion of these structures. Asahina (1954) referred to the labial part bearing the lateral lobes as "mentum" and the more proximal part as the "submentum". This view implies a bilobed prementum (the lobe and the prementum as termed in the present article) and the loss (instead of a fusion) of the galea and lacinia. We do not follow this interpretation based on the insertion of $\mathrm{M}$. submentopraementalis (0la8), which generally defines the posterior margin of the prementum.

The labial palps of odonates underwent some unique specializations, more conspicuous in the larvae, but still distinct in the adult despite the strongly modified function. They are characterized by the reduction of the number of palpomeres $(102: 1)$ together with a dorsoventral flattening (103:1), a drastically increased length (104:0), and moveable spine-like hooks (105: 1) devoid of muscles. Due to their flat shape and the increased stiffness (realized by palpomere reduction) the palps are very well suited to counter the high transverse mechanical strain produced when catching and clamping prey. The hooks function as spines for penetrating and fixing the prey.

In the maxilla the outer lobe can be homologized with the palpus based on the muscle insertions (0la13, 0la14). We consider the mesal lobe as the lacinia. It was shown in a developmental study that no galea is formed in the embryo (Ando, 1962). Additionally, there is no trace of muscles in the adult or larval stages. Thus, we conclude that the galea is completely reduced in Odonata. Accordingly, we refute the term "galeolacinia", which implies a fusion of the outer and inner endite lobes (Ax, 1999). Staniczek $(2000,2001)$ demonstrated that mayflies, albeit also lacking galeal muscles, exhibit a "real" galeolacinia containing elements of both endite lobes. Both are clearly distinguishable and connected along their entire length by a membranous field. Thus, the loss of M. stipitogalealis $(0 \mathrm{mx} 7 ; 88: 1)$ is a potential synapomorphy of Ephemeroptera and Odonata.

Wing-like tentorial processes reaching inside the lumen of the mandible $(49: 1)$ have not yet been encountered in neopterans. They are shared with Lepisma and other Zygentoma (Koch, 2003), but we found no comparable structures in the examined ephemeropterans and there are no records in the literature (Staniczek, 2001; Strenger, 1952, 1954, 1970, 1975). Consequently, these tentorial protuberances are a potential autapomorphy of Odonata.

In summary, incomplete, inaccurate, and misinterpreted information on the head of Odonata was one of the main reasons for the widely accepted Metapterygota hypothesis. Our reassessment of the odonate head morphology clearly shows that dragonflies lack some of the metapterygotan features formerly proposed in the literature.

\section{Conclusions and outlook}

The present investigation shows, in contrast to earlier studies, that characters of the head support a Palaeoptera clade. The three main possibilities, Palaeoptera, Chiastomyaria, and Metapterygota, are supported by arguments derived from different body parts. Each option implies homoplasy in some of these characters. A principal problem related to far-reaching evolutionary transformations in the early evolution of Pterygota is the problematic or impossible polarity determination of several thoracial and abdominal characters, due to the absence of corresponding features in all potential apterygote outgroups. These problems can be avoided by evaluating characters of the head, the approach followed in this study. As shown earlier (see, for example, Beutel and Baum, 2008; Beutel et al., 2010) the evaluation of a limited character system can easily lead to erroneous phylogenetic results. Therefore, the results presented here should be critically re-evaluated in the framework of very broad analyses, especially of extensive molecular data. Past morphological studies gave the impression that the basal splitting events of winged insects are based on robust theories derived from mandible anatomy. The present study shows that this is by no means true. Even though the phylogenetic hypothesis presented here may be preliminary, the well-documented data will allow a better understanding of character transformations in the early evolution of Pterygota. A stepwise progress in this direction will also reveal possible interconnections of different characters and character systems (hidden character weighing) and features which require more detailed investigations. This process will probably lead to a well-founded and detailed evolutionary scenario of the winged insects, arguably the most successful group of organisms.

\section{Acknowledgement}

We thank Dr A. Staniczek and Prof. Ryu Machida for providing valuable specimens for this study. Sincere thanks also go to Fabian Wilde (HZG, Geesthacht), Sebastian Thieß, Wolfgang Drube (DESY, Hamburg) as well as Marco Stampanoni and Peter Modregger (both SLS, Villigen, Switzerland) for making high quality SR-microCT investigations possible. The SR-microCT investigations were conducted through project applications I-20080169 and I-20090211 (DESY, 
Hamburg) and 20110069 (SLS, Villigen, Switzerland). Irina Ruf (Steinmann Institute, Bonn, Germany) enabled microCT investigations at the Steinmann Institute. Claudia Etzbauer, Manuela Thelen, and Johannes Dambach (all ZFMK) provided excellent support in the laboratory and field. The program TNT is being made available with the sponsorship of the Willi Hennig Society.

\section{References}

Albrecht, F.O., 1953. The Anatomy of the Migratory Locust. The Athlone Press, London.

Allman, E.S., Holder, M.T., Rhodes, J.A., 2009. Estimating trees from filtered data: identifiability of models for morphological phylogenetics. J. Theor. Biol. 263, 108-119.

Ando, H., 1962. The Comparative Embryology of Odonata with Special Reference to a Relic Dragonfly, Epiophlebia superstes. The Japan Society for the Promotion of Science, Tokyo

Asahina, S., 1954. A Morphological Study of a Relic Dragonfly Epiophlebia superstes Selys (Odonata, Anisozygoptera). The Japan Society for the Promotion of Science, Tokyo.

Ax, P., 1999. Das System der Metazoa II-Ein Lehrbuch der phylogentischen Systematik. Akademie der Wissenschaften und der Literatur, Mainz.

Badonnel, A., 1934. Recherches sur l'anatomie des Psoque. Bull. biol. France Belgique. Suppl. 18, 1-241.

Bechly, G., Brauckmann, C., Zessin, W., Gröning, E., 2001. New results concerning the morphology of the most ancient dragonflies (Insecta: Odonatoptera) from the Namurian of Hagen-Vorhalle (Germany). J. Zoolog. Syst. Evol. Res. 39, 209-226.

Beckmann, F., Herzen, J., Haibel, A., Müller, B., Schreyer, A., 2008. High density resolution in synchrotron-radiation-based attenuation-contrast microtomography. Proceedings of SPIE 7078:70781D-3.

Beutel, R.G., Baum, E., 2008. A longstanding entomological problem finally solved? Head morphology of Nannochorista (Mecoptera, Insecta) and possible phylogenetic implications. J. Zool. Syst. Evol. Res. 46, 346-367.

Beutel, R.G., Vilhelmsen, L., 2007. Head anatomy of Xyelidae (Hexapoda: Hymenoptera) and phylogenetic implications. Organisms Div. Evol. 7, 207-230.

Beutel, R.G., Weide, D., 2005. Cephalic anatomy of Zorotypus hubbardi (Hexapoda: Zoraptera): new evidence for a relationship with Acercaria. Zoomorphology, 124, 121-136.

Betz, O., Wegst, U., Weide, D., Heethoff, M., Helfen, L., Lee, W.-K., Cloetens, P., 2007. Imaging applications of synchrotron X-ray phase-contrast microtomography in biological morphology and biomaterials science. I. General aspects of the technique and its advantages in the analysis of millimetre-sized arthropod structure. J. Microsc. 227, 51-71.

Beutel, R.G., Gorb, S., 2006. A revised interpretation of the evolution of attachment structures in hexapoda with special emphasis on Mantophasmatodea. Arthropod Syst. Phylogeny 64, 3-25.

Beutel, R.G., Friedrich, F., Hörnschemeyer, T., Pohl, H., Hünefeld, F., Beckmann, F., Meier, R., Misof, B., Whiting, M.F., Vilhelmsen, L., 2010. Morphological and molecular evidence converge upon a robust phylogeny of the megadiverse Holometabola. Cladistics 26, 1-15.

Bitsch, C., Bitsch, J., 2002. The endoskeletal structures in arthropods: cytology, morphology and evolution. Arthropod Struct. Dev. 30, 159-177.

Boudreaux, B.H., 1979. Arthropod Phylogeny with Special Emphasis to Insects. Wiley, New York.
Brauckmann, C., Zessin, W., 1989. Neue Meganeuridae aus dem Namurium von Hagen-Vorhalle (BRD) und die Phylogenie der Meganisoptera (Insecta, Odonata). Deut. Entomol. Z. 36, 177-215.

Chaudonneret, J., 1948. Le labium des Thysanoures (Insectes Aptérygotes). Ann. Sci. Nat. Zool. Biol. Anim. 10, 1-27.

Chaudonneret, J., 1950. La morphologie céphalique de Thermobia domestica (Packard) (Insecte aptérygogte Thysanoure). Ann. Sci. Nat. Zool. Biol. Anim. 11, 145-302.

Chapman, R.N., 1918. The basal connection of the tracheae of the wings of insects. In: Comstock, J.H. (Ed), The Wings of Insects. Cornell University Press, Ithaca, NY, pp. 27-51.

Crampton, G.C., 1924. The phylogeny and classification of insects. J. Entomol. Zoolog. 16, 33-47.

Denis, J.R., Bitsch, J., 1973. Morphologie de la tête des Insects. In: Grassé, P.-P.(Ed.), Traité de Zoologie. Masson, Paris, Vol. 8, pp. 27-51.

DuPorte, E.M., 1946. Observations on the morphology of the face in insects. J. Morphol. 79, 371-417.

DuPorte, E.M., 1957. The comparative morphology of the insect head. Annu. Rev. Entomol. 2, 55-70.

Edmunds, G.F.J., 1988. The mayfly subimago. Annu. Rev. Entomol. 33, 509-527.

Engel, M.S., Grimaldi, D.A., 2004. New light shed on the oldest insect. Nature 427, 627-630.

Fiala, J.C., 2005. Reconstruct: a free editor for serial section microscopy. J. Microsc. 218, 52-61.

Friedemann, K., Wipfler, B., Bradler, S., Beutel, R., 2012. On the head morphology of Phyllium and the phylogenetic relationships of Phasmatodea (Insecta). Acta Zoologica 93, 184-199.

Friedrich, F., Beutel, R., 2010. Goodbye Halteria? The thoracic morphology of Endopterygota (Insecta) and its phylogenetic implications Cladistics 26, 1-34.

Friedemann, K., Wipfler, B., Bradler, S., Beutel, R., 2012. On the head morphology of Phyllium and the phylogenetic relationships of Phasmatodea (Insecta). Acta. Zool. 93, 184-199.

Gaunt, M.W., Miles, M.A., 2002. An insect molecular clock dates the origin of the insects and accords with palaeontological and biogeographic landmarks. Mol. Biol. Evol. 19, 748-761.

Goloboff, P.A., Farris, J.S., Nixon, K.C., 2008. TNT, a free program for phylogenetic analysis. Cladistics 24, 774-786.

Gorb, S.N., 1999. Evolution of the dragonfly head-arresting system. Proc. R. Soc. Lond. B Biol. Sci. 266, 525-535.

Grimaldi, D., Engel, M.S., 2005. Evolution of the Insects. Cambridge University Press, NY.

Haas, F., Kukalová-Peck, J., 2001. Dermapteran hindwing structure and folding: New evidence for familial, ordinal and superordinal relationships within Neoptera (Insecta). Eur. J. Entomol. 98, 445509.

Hakim, Z.M., 1964. Comparative anatomy of the head capsules of adult Odonata. Ann. Entomol. Soc. Am. 57, 267-278.

Hennig, W., 1969. Die Stammesgeschichte der Insekten. Waldemar Kramer, Frankfurt am Main.

Hovmöller, R., Pape, T., Kallersjo, M., 2002. The Palaeoptera problem: basal pterygote phylogeny inferred from $18 \mathrm{~S}$ and $28 \mathrm{~S}$ rDNA sequences. Cladistics 18, 313-323.

Hudson, G.B., 1951. Studies on the comparative anatomy and systematic importance of the hexapod tentorium-IV. Ephemeroptera. J. Entomol. Soc. South. Afr. 14, 3-23.

Huelsenbeck, J.P., Bollback, J.P., 2001. Empirical and hierarchical bayesian estimation of ancestral states. Syst. Biol. 50, 351-366.

Ishiwata, K., Miyata, T., Su, Z.H., 2011. Phylogenetic analysis of winged insects based on several nuclear protein-coding genes. Genes Genet. Syst. 85, 398.

Jacobs, W., Seidel, F., 1975. Wörterbuch der Biologie, Systematische Zoologie: Insekten. Gustav Fischer Verlag, Jena.

Jukes, T.H., Cantor, C.R., Munro, H.N., 1969. Evolution of Protein Molecules. Academic Press, New York. 
Kadam, K., 1961. Studies on the morphology of an Indian earwig, Labidura riparia, Pall., var. ineris, Brunner. J. Zool. Soc. India, 13, 34-49.

Kjer, K., 2004. Aligned 18S and insect phylogeny. Syst. Biol. 53, 506-514.

Kjer, K., Carle, F.L., Litman, J., Ware, J., 2006. A molecular phylogeny of hexapoda. Arthropod Syst. Phylogeny 64, 35-44.

Klass, K.-D., 2007. Die Stammesgeschichte der Hexapoden: eine kritische Diskussion neuerer Daten und Hypothesen. Denisia 20, 413-450.

Klass, K.-D., 2008. The female abdomen of ovipositor-bearing Odonata (Insecta: Pterygota). Arthropod Syst. Phylogeny 66, 45142.

Klass, K.D., 2009. A critical review of current data and hypotheses on hexapod phylogeny. Proc. Arthropod Embryol. Soc. Jpn. 43, 3 22.

Koch, M., 2003. Towards a phylogenetic system of the Zygentoma. Entomol. Abh. 62, 122-125.

Kristensen, N.P., 1975. The phylogeny of hexapod "orders". A critical review of recent accounts. J. Zoolog. Syst. Evol. Res. 13, 1-44.

Kristensen, N.P., 1981. Phylogeny of insect orders. Annu. Rev. Entomol. 26, 135-157.

Kristensen, N.P., 1991. Phylogeny of extant hexapods. In: Naumann, J.D., Carne, P.B., Lawrence, J.F. (Eds.), The Insects of Australia, Vol. 1. Cornell University Press, Ithaca, New York, pp. 125-140.

Kristensen, N.P., 1998. The groundplan and basal diversification of hexapods. In: Fortey, R.A., Thomas, R.H. (Eds), Arthropod Relationships. Chapman \& Hall, London, pp. 281-293.

Kukalova-Peck, J., 1978. Origin and evolution of insect wings and their relation to metamorphosis, as documented by the fossil record. J. Morphol. 156, 53-125.

Kukalová-Peck, J., 1991. Fossil history and the evolution of hexapod structures. In: Naumann, J.D., Carne, P.B., Lawrence, J.F. (Eds.), The Insects of Australia, Vol. 1. CSIRO, Ithaca, New York.

Kukalová-Peck, J., 1983. New Homoiopteridae (Insecta: Paleodictyoptera) with wing articulation from Upper Carboniferous strata of Mazon Creek, Illinois. Can. J. Zool. 61, 1670 1687.

Kukalová-Peck, J., 1997. Arthropod phylogeny and 'basal' morphological structures. In: Fortey, R.A., Thomas, R.H. (Eds.), Arthropod Relationships, Systematics Association Special Volume Series 55. Chapman \& Hall, London, pp. 249-268.

Kukalová-Peck, J., 2008. Phylogeny of higher taxa in Insecta: finding synapomorphies in the extant fauna and separating them from homoplasies. Evol. Biol. 35, 4-51.

La Greca, M., 1980. Origin and evolution of wings and flight in insects. Bull. Zool. 47 (Suppl.), 65-82.

Lewis, P.O., 2001. A likelihood approach to estimating phylogeny from discrete morphological character data. Syst. Biol. 50, 913-925.

Lin, C.-P., Chen, M.-Y., Huang, J.-P., 2010. The complete mitochondrial genome and phylogenomics of a damselfly, Euphaea formosa support a basal Odonata within the Pterygota. Gene 468, 20-29.

Lohmann, H., 1996. Das phylogenetische System der Anisoptera (Odonata). Entomol. Z. 106, 209-266.

Mallatt, J., Giribet, G., 2006. Further use of nearly complete 28 S and 18S rRNA genes to classify Ecdysozoa: 37 more arthropods and a kinorhynch. Mol. Phylogenet. Evol. 40, 772-794.

Martynow, A.V., 1924. Über zwei Grundtypen der Flügel bei den Insekten und deren Evolution. Z. Morph. Öko. Tiere 4, 465501 .

Mathur, K.C., 1962. The musculature of the head capsule and mouthparts of adult Pantala flavescens (Fabricius) (Odonata, Anisoptera, Libellulidae, Libellulinae). J. Anim. Morphol. Physiol. 9, 18-31.

Mathur, P.N., Mathur, K.C., 1961. Studies on the cephalic musculature of adult Ictinus angulosus Selys (Odonata, Anisoptera, Gomphidae, Ictinae). J. Morphol. 109, 237-249.
Matsuda, R., 1965. Morphology and evolution of the insect head. Memoirs of the AEI, Michigan 4, 1-334.

Matsuda, R., 1970. Morphology and evolution of the insect thorax. Mem. Entomol. Soc. Can. 76, 1-431.

Matsuda, R., 1981. The origin of insect wings (Arthropoda, Insecta). Int. J. Insect Morphol. Embryol. 10, 387-398.

Matushkina, N.A., 2008a. The ovipositor of the relic dragonfly Epiophlebia superstes: a morphological re-examination (Odonata: Epiophlebiidae). Int. J. Odonatol. 11, 71-80.

Matushkina, N.A., 2008b. Skeletomuscular development of genital segments in the dragonfly Anax imperator (Odonata, Aeshnidae) during metamorphosis and its implications for the evolutionary morphology of the insect ovipositor. Arthropod Struct. Dev. 37, 321-332.

Moulins, M., 1968. Contribution a la connaissance anatomique des plécoptères: la région céphalique de la larve de Neomoura cinera (Neomouridae). Ann. Soc. Entomol. France, 4, 91-143.

Nixon, K.C., 2002. Winclada ver. 1.00.08 Published by the author, Ithaca, NY.

Ogden, T.H., Whiting, M.F., 2003. The problem with "the Paleoptera Problem": sense and sensitivity. Cladistics 19, 432-442.

Ott, M., Zola, J., Aluru, S., Stamatakis, A., 2007. Large-scale maximum likelihood-based phylogenetic analysis on the IBM BlueGene/L. Presented at: ACM/IEEE Supercomputing Conference 2007. Reno, NV, USA.

Pass, G., 1991. Antennal circulatory organs in Onychophora, Myriapoda and Hexapoda-functional morphology and evolutionary implications. Zoomorphology 110, 145-164.

Pass, G.N., 2000. Accessory pulsatile organs: evolutionary innovations in insects. Annu. Rev. Entomol. 45, 495-518.

Pass, G., Gereben-Krenn, B.-A., Merl, M., Plant, J., Szucsich, N.U., Tögel, M., 2006. Phylogenetic relationships of the orders of Hexapoda: contributions from the circulatory organs for a morphological data matrix. Arthropod Syst. Phylogeny 64, 165203.

Pfau, H.K., 1986. Untersuchungen zur Konstruktion, Funktion und Evolution der Libellen (Insecta, Odonata). Tijdschr. Entomol. 129, $35-123$.

Pfau, H.K., 1991. Contributions to the functional morphology to the phylogenetic systematics of Odonata. Adv. Odonatol. 5, 109-141.

Pfau, H.K., 2002. Tandem grip mechanics and tandem linkage shifting in Odonata - reconstruction of evolution and phylogenetic significance. Int. J. Odonatol. 5, 129-179.

Pfau, H.K., 2005. Structure, function and evolution of the 'glans' of the anisopteran vesica spermalis (Odonata). Int. J. Odonatol. 8, 259-310.

Plazzi, F., Ricci, A., Passamonti, M., 2011. The mitochondrial genome of bacillus stick insects (Phasmatodea) and the phylogeny of orthopteroid insects. Mol. Phylogenet. Evol. 58, 304-316.

Pohl, H., 2010. A scanning electron microscopy specimen holder for viewing different angles of a single specimen. Microsc. Res. Tech. 73, 1073-1076.

Rähle, W., 1970. Untersuchungen an Kopf und Prothorax von Embia ramburi Rimsky-Korsakov 1906 (Embioptera, Embiidae). Zoologische Jahrbücher, Abt. Anat. Ontog. Tiere, 87, 248-330.

Rokas, A., Carroll, S.B., 2006. Bushes in the tree of life. PLoS Biol. 4, e352.

Ronquist, F., Huelsenbeck, J.P., 2003. MrBayes 3: Bayesian phylogenetic inference under mixed models. Bioinformatics 19, 1572-1574.

Schönmann, H., 1981. Zur Kopfmorphologie der Ephemeridenlarven Siphlonurus aestivalis Rsyon und Lepeorus goyi goyi Peters. Zoologica 131, 1-51.

Seifert, G., 1995. Entomologisches Praktikum. Georg Thieme Verlag, Stuttgart.

Short, J.R.T., 1955. The morphology of the head of Aeshna cyanea (Müller) (Odonata, Anisoptera). Trans. Royal Entomol. Soc. London 106, 197-211. 
Simm, K., 1914. Die larvalen Mundwerkzeuge bei Oligoneuria rhenana und ihre Verkümmerung bei Imago. Bull. Acad. sci. Cracovie 4, 387-396.

Simon, S., Strauss, S., von Haeseler, A., Hadrys, H., 2009. A phylogenomic approach to resolve the basal pterygote divergence. Mol. Biol. Evol. 26, 2719-2730.

Simon, S., Schierwater, B., Hadrys, H., 2010. On the value of elongation factor-1[alpha] for reconstructing pterygote insect phylogeny. Mol. Phylogenet. Evol. 54, 651-656.

Snodgrass, R.E., 1935. Principles of Insect Morphology. McGraw-Hill Publications in the Zoological Sciences, New York.

Snodgrass, R.E., 1947. The insect cranium and the "epicranial suture". Smith. Misc. Coll. 107, 1-52.

Soldán, T., 1997. The Ephemeroptera — whose sistergroup are they? In: Landolt, P., Sartori, M. (Eds.), Ephemeroptera \& Plecoptera: Biology-Ecology - Systematics. Mauron, Tingucley \& Lachat, Fribourg, Switzerland, pp. 514-519.

Soldán, T., 1997. The Ephemeroptera: whose sistergroup are they? In: Landholt, P., Sartori, M. (Eds.), Ephemeroptera \& Plecoptera: Biology-Ecology-Systematics. Mauron, Tingucley \& Lachat, Fribourg, Switzerland, pp. 514-519.

Soldán, T., 2003. Ephemeroptera phylogeny and higher classification: present status and conflicting hypotheses. Entomol. Abh. 61, 125126.

Stamatakis, A., 2006. RAxML-VI-HPC: maximum likelihood-based phylogenetic analyses with thousands of taxa and mixed models. Bioinformatics 22, 2688-2690.

Stamatakis, A., Ludwig, T., Meier, H., 2005. RAxML-III: a fast program for maximum likelihood-based inference of large phylogenetic trees. Bioinformatics 21, 456-463.

Staniczek, A.H., 2000. The mandible of silverfish (Insecta : Zygentoma) and mayflies (Ephemeroptera): Its morphology and phylogenetic significance. Zool. Anz. 239, 147-178.

Staniczek, A.H., 2001. Der Larvenkopf von Oniscigaster wakefieldi McLachlan, 1873 (Insecta: Ephemeroptera: Oniscigastridae). Ein Beitrag zur vergleichenden Anatomie und Phylogenie der Eintagsfliegen. PhD thesis, Eberhard-Karls-Universität Tübingen.

Strenger, A., 1952. Die funktionelle und morphologische Bedeutung der Nähte am Insektenkopf. Zool. Jahrb. 72, 468-521.

Strenger, A., 1954. Zur Kopfmorphologie der Ephemeridenlarven. Erster Teil. Ecdyonurus und Rhithrogena. Öster. Zool. Z. 4, 191-228.

Strenger, A., 1970. Zur Kopfmorphologie der Ephemeridenlarven Palingenia longicauda. Zoologica 117, 1-26.

Strenger, A., 1975. Zur Kopfmorphologie der Ephemeridenlarven Ephemera danica. Zoologica 123, 2-22.

Strenger, A., 1977. Zur Kopfmorphologie der Ephemeridenlarven Proboscidiplocia skorai. Zoologica 127, 1-18.

Terry, M.D., Whiting, M.F., 2005. Mantophasmatodea and phylogeny of the lower neopterous insects. Cladistics 21, 240-258.

Tilgner, E.H., Kiselyova, T.G., McHugh, J.V., 1999. A morphological study of Timema cristinae vickery with implications for the phylogenetics of phasmida. Deut. Entomol. Z. 46, 149-162.

Tillyard, R.J., 1917. The Biology of Dragonflies (Odonata or Paraneuroptera). University Press, Cambridge.

Tillyard, R.J., 1928. The larva of Hemiphlebia mirabilis Selys (Odonata). Proc. Linnean Soc. NSW 53, 193-206.

Torre-Bueno, J.R.D.L., Nichols, S.W., Tulloch, G.S., Schuh, R.T., 1989. The Torre-Bueno Glossary of Entomology. New York Entomological Society in cooperation with the American Museum of Natural History, New York.

Walker, E.M., 1931. On the anatomy of Grylloblatta campodeiformis Walker 1. Exoskeleton and musculature of the head. Ann. Entomol. Soc. Am. 24, 519-536.

Whedon, A.D., 1918. The comparative morphology and possible adaptations of the abdomen in the Odonata. Trans. Am. Entomol. Soc. 73, 373-446.
Wheeler, W.C., Whiting, M., Wheeler, Q.D., Carpenter, J.M., 2001. The phylogeny of the extant hexapod orders. Cladistics 17, 113169.

Whitfield, J.B., Kjer, K.M., 2008. Ancient rapid radiations of insects: challenges for phylogenetic analysis. Annu. Rev. Entomol. 53, 449472.

Whitfield, J.B., Lockhart, P.J., 2007. Deciphering ancient rapid radiations. Trends Ecol. Evol. 22, 258-265.

Willkommen, J., 2009. The tergal and pleural wing base sclerites - homologous within the basal branches of Pterygota? Aquat. Insects 31, 443-457.

Willkommen, J., Hörnschemeyer, T., 2007. The homology of wing base sclerites and flight muscles in Ephemeroptera and Neoptera and the morphology of the pterothorax of Habroleptoides confusa (Insecta: Ephemeroptera: Leptophlebiidae). Arthropod Struct. Dev. 36, 253-269.

Wipfler, B., Machida, R., Müller, B., Beutel, R.G., 2011. On the head morphology of Grylloblattodea (Insecta) and the systematic position of the order, with a new nomenclature for the head muscles of Dicondylia. Syst. Entomol. 36, 241-266.

Wipfler, B., Wieland, F., DeCarlo, F., Hörnschemeyer, T., 2012. Cephalic morphology of Hymenopus coronatus (Insecta: Mantodea) and its phylogenetic implications. Arthropod Struct. Dev. 41, 87-100.

Wipfler, B., Wieland, F., DeCarlo, F., Hörnschemeyer, T., 2012. Cephalic morphology of Hymenopus coronatus (Insecta: Mantodea) and its phylogenetic implications. Arthropod Struct. Dev. 41, 87-100.

Witte, H., Doring, D., 1999. Canalized pathways of change and constraints in the evolution of reproductive modes of microarthropods. Exp. Appl. Acarol. 23, 181-216.

Yang, Z., 1994. Maximum likelihood phylogenetic estimation from DNA sequences with variable rates over sites: approximate methods. J. Mol. Evol. 39, 306-314.

Zhang, J., Zhou, C., Gai, Y., Song, D., Zhou, K., 2008. The complete mitochondrial genome of Parafronurus youi (Insecta: Ephemeroptera) and phylogenetic position of the Ephemeroptera. Gene 424, 18-24.

Zhang, Y.-Y., Xuan, W.-J., Zhao, J.-L., Zhu, C.-D., Jiang, G.-F., 2010. The complete mitochondrial genome of the cockroach Eupolyphaga sinensis (Blattaria: Polyphagidae) and the phylogenetic relationships within the Dictyoptera. Mol. Biol. Rep. 37, 3509-3516.

\section{Supporting Information}

Additional Supporting Information may be found in the online version of this article:

Data S1. Sheet 1: homologized head musculature between studied taxa and literature. Sheet 2: list of the origin and insertion for every head muscle. Sheet 3: studied taxa and literature sources (Table 2).

Data S2. Character matrix used for phylogenetic analysis.

Data S3. Character discussion.

Data S4. Three-dimensional model of the head of Lestes virens. The program "Blender" can be obtained free of charge under the GPL licence from http://www.blender.org. For instructions on how to use the program, please go to http://wiki.blender.org/index.php/Doc:Manual. The file can be opened directly with the program.

Please note: Wiley-Blackwell is not responsible for the content or functionality of any supplementary materials supplied by the authors. Any queries (other than missing material) should be directed to the corresponding author for the article. 


\section{Appendix}

Characters used for construction of the morphological data matrix. 0 . Orientation of head: (0) orthognathous; (1) prognathous or slightly inclined; (2) hypognathous.

1. Number of ocelli: (0) 0; (1) 2; (2) 3 .

2. Compound eyes: (0) composed of more than 80 ommatidia; (1) fewer than 80 ommatidia.

3. Distance between eyes: (0) less than their own width; (1) greater than their own width; (2) eyes fused at single point; (3) eyes broadly fused along an eye seam.

4. Shape of vertex: (0) flat, not developed into large protuberance; (1) conical, or developed into a large transverse ridge.

5. Epicranial or coronal suture: (0) present; (1) absent.

6. Parietal ridge: (0) absent; (1) present.

7. Postoccipital ridge: (0) present; (1) absent.

8. Subgenal ridge: (0) absent; (1) present.

9. Pleurostomal ridge and circumantennal ridge: (0) partly in contact; (1) not in contact.

10. Pleurostomal ridge and circumoccular ridge: $(0)$ not in contact; (1) partly in contact.

11. Interantennal ridge: (0) absent; (1) present.

12. Shape of frons: (0) flat when seen from lateral; (1) grossly enlarged when seen from lateral.

13. Distinct convexity ventrad of antennal bases: (0) absent; (1) present.

14. Scutellum: (0) absent; (1) present.

15. X-shaped median apodeme on the frontal region: (0) absent; (1) present.

16. Clypeus: (0) not subdivided; (1) subdivided into ante- and postclypeus.

17. Postclypeus: (0) normally developed; (1) enlarged.

18. Anteclypeus: (0) membranous; (1) sclerotized.

19. Adult mouthparts: (0) with function; (1) without function.

20. Oval sclerotization of labral base: (0) absent; (1) present.

21. Tormae: (1) absent; (0) present.

22. Mesal extension of tormae: (0) present; (1) absent.

23. M. epistoepipharyngealis (0lb3): (0) present; (1) absent.

24. M. labroepipharyngalis (0lb5): (0) present; (1) absent.

25. M. labrolabralis (0lb6): (0) present; (1) absent.

26. Insertion of antennae: (0) close to the anterior mandibular articulation; (1) distinctly separated from the anterior mandibular articulation.

27. Antennifer: (0) present; (1) absent.

28. Length of pedicel and scapus: (0) pedicel longer than scapus; (1) scapus longer than pedicel; (2) scapus and pedicel equal in length.

29. Oval scerite in membrane connecting scapus and pedicellus: $(0)$ absent; (1) present.

30. Size of first flagellomere: (0) not enlarged; (1) distinctly enlarged.

31. Antennal stridulatory organ: (0) absent; (1) present.

32. Areas of origin of antennal muscles: (0) anterior tentorial arms only; (1) anterior and dorsal tentorial arms; (2) on dorsal tentorial arms only; (3) on dorsal arms and tentorial bridge.

33. M. tentorioscapalis lateralis (0an3): (0) present; (1) absent.

34. M. tentorioscapalis medialis (0an4): (0) present; (1) absent.

35. Circumesophageal vessel ring branching off the dorsal aorta posterior to the brain: (0) present; (1) absent.

36. Ostia of dorsal vessel: (0) lips always present; (1) ostia with and without lips (excurrent ostia).

37. Position and number of excurrent ostia within a segment: (0) one ventrolateral pair; (1) ventromedian.

38. Antennal circulatory organs in adults: (0) present; (1) absent.

39. Antennal vessel wall: (0) uniform; (1) bipartite.
40. Contractibility of antennal ampulla: (0) absent (non-pulsatile); (1) present (pulsatile)

41. M. interampullaris (0ah1): (0) absent; (1) present.

42. M. ampulloaortica (0ah2): (0) absent; (1) present.

43. M. ampullopharyngealis (0ah3): (0) absent; (1) present.

44. M. ampullo-frontalis (0ah4): (0) absent; (1) present.

45. Connection of antennal ampulla to supraoesophageal ganglion: (0) absent; (1) present.

46. Oval nuclei in tissue connecting the antennal ampulla and supraoesophageal ganglion: (0) absent; (1) present.

47. Anterior and posterior tentorium: (0) separated; (1) merged.

48. Anterior tentorial pit: (0) not visible from outside; (1) externally visible.

49. Transverse mandibular tendon: (0) present; (1) absent.

50. Wing-like processes of the anterior tentorial apodemes extending into the lumen of the mandibular base: $(0)$ absent; (1) present.

51. Corpotentorium: (1) elongated; (0) slim.

52. Apophyses on the anterior surface of the corpotentorium: (0) absent; (1) present.

53. Secondary anterior tentorial bridge ("perforation of the corpotentorium"): (0) absent; (1) present.

54. Lateral lobes on the anterior tentorial arms: (0) absent; (1) present.

55. Cuticular dorsal tentorial arms: (0) absent; (1) present.

56. Trabeculae tentorii of posterior tentorial arms: (0) present; (1) absent.

57. M. tentoriofrontalis posterior (0te1): (0) present; (1) absent.

58. M. posteriotentorialis (0te4): (0) present; (1) absent.

59. M. tentoritentorialis longis (0te5): (0) present; (1) absent.

60. M. tentoritentorialis brevis (0te6): (0) present; (1) absent.

61. Numbers of incisivi on the left mandible: (0) 2 ; (1) 3 ; (2) 5 ; (3) 0 ;

(4) 1 ; (5) 4

62. Numbers of incisivi on the right mandible: (0) 2 ; (1) 3 ; (2) 4 ; (3) 5 ; (4) $0 ; 5(1)$.

63. Armament on the mesal side of the left mandible: (0) without teeth or ridges; (1) one tooth; (2) three ridges.

64. Dorsal cutting edge of the left mandible: (0) notched; (1) smooth.

65. Mandibular postmola: (0) absent; (1) present.

66. Anterior mandibular joint: (0) absent; (1) present.

67. Anterior mandibular joint: (0) cuticular hardening on the mandibular depression; (1) channel-joint; (2) ball-and-socket joint.

68. Anterolateral part of the anterior mandibular articulation (paratentorial joint): (0) present; (1) absent.

69. Posterior mandibular joint: (0) cylinder-shaped (1) ball-andsocket joint.

70. M. craniomandibularis externus anterior (0md2): (0) present; (1) absent.

71. M. hypopharyngomandibularis (0md4): (0) present; (1) absent.

72. M. tentorio-mandibularis lateralis superior $(0 \mathrm{md})$ : $(0)$ present; (1) absent.

73. M. tentorio-mandibularis medialis superior $(0 \mathrm{md} 7)$ : (0) present; (1) absent.

74. Cardo: (0) present; (1) absent.

75. Division of stipes into bastistipes and mediastipes: (0) present; (1) absent.

76. Galea: (0) present; (1) absent.

77. Distal field of trichomes on the galea: (0) undivided; (1) divided;

(2) just a U-shaped seam.

78. Connection of lacinia and galea: (0) separated; (1) fused.

79. Shape of lacinia: (0) sickle-shaped; (1) chisel-shaped; (2) truncate; (3) short claw.

80. Mesally directed setae on lacinia: (0) present; (1) absent. 
81. Lacinia: (0) free; (1) in galeal cavity.

82. Lacinial incisivi: (0) present; (1) absent.

83. Number of incisivi on lacinia: (0) 3 ; (1) 2 ; (2) 1 ; (3) more than 3.

84. Dentisetae on lacinia: (0) present; (1) absent.

85. Proximal apodeme on the lacinia: (0) absent; (1) present.

86. Galeolobulus: (0) absent; (1) present.

87. Maxillary palp: (0) 5-segmented; (1) 4-segmented; (2) 1segmented; (3) 3-segmented; (4) 6-segmented; (5) 7-segmented.

88. Orientation of maxillary palps: (0) ventrally oriented; (1) anteriorly or dorsally directed.

89. 0mx7: (0) present; (1) absent.

90. M. palpopalpalis maxillae primus $(0 \mathrm{mx} 12)$ : (0) present; (1) absent.

91. Postmentum: (0) not subdivided; (1) subdivided into submentum and mentum.

92. Angle between submentum and mentum: $(0)<60^{\circ}$ or absent; (1) more than $60^{\circ}$.

93. Curvature of submentum: (0) absent; (1) curved in lateral view. 94. Median longitudinal tunnel of labium: (0) absent; (1) present.

95. Median cleft of prementum: (0) absent; (1) present.

96. Labium: (0) paraglossa and glossa separated; (1) paraglossa and glossae completly fused.

97. Glossa: (0) present; (1) reduced.

98. Number of glossae: (0) 2; (1) 1.

99. Number of paraglossae: (0) 2; (1) 1.

100. Shape of paraglossa: (0) cylindrical, as wide as thick; (1) flat, wider than thick; (2) palp-like.

101. Relative length of paraglossae and glossae: (0) about equally long; (1) paraglossae twice as long or longer.

102. Orientation of labial palpi: (0) anteriorly or laterally; (1) ventrally or posteriorly.

103. Number of labial palpomeres: (0) 3; (1) 1; (2) 2; (3) 4.

104. Shape of labial palps: (0) approximately round in cross-section; (1) dorsoventrally flattened.

105. Length of labial palps: (0) longer than glossae; (1) about as long as the glossae.

106. Moveable hooks of labial palpi: (0) absent; (1) present.

107. M. postoccipitoglossalis medianus (0la1): (0) present; (1) absent.

108. M. postoccipitoglossalis lateralis (0la2): (0) present; (1) absent.
109. M. postoccipitoparaglossalis (0la3): (0) present; (1) absent. 110. M. postoccipitoprementalis (0la4): (0) present; (1) absent. 111. 0la5: (0) present; (1) absent.

112. Origin of M. tentoriopraementalis inferior 0la5 (M.29): (0) ventral apodeme; (1) posterior tentorial arms.

113. M. tentorioparaglossalis (0la6): (0) present; (1) absent.

114. Origin of M. tentorioparaglossalis (0la6): (0): tentorium; (1) basal edge of prementum.

115. M. tentorioglandularis (0la7): (0) present; (1) absent.

116. M. submentopraementalis (0la8): (0) present; (1) absent.

117. M. submentopraementalis (0la8): (0) one component; (1) two components.

118. M. postmentomembranus (0la9): (0) present; (1) absent.

119. M. submentomentalis (0la10): (0) absent; (1) present.

120. 0la11: (0) present; (1) absent.

121. M. praementoglossalis (0la12): (0) present; (1) absent.

122. 0la13: (0) present; (1) absent.

123. 0la14: (0) present; (1) absent.

124. Hypopharynx overlapping paraglossae and glossae: (0) absent;

(1) present.

125. Shape of hypopharynx: (0) slope like; (1) distinctly flattened. 126. Superlinguae: (0) present; (1) absent.

127. Salivary glands and ductus: (0) present; (1) absent.

128. Connection of salivary ducts: (0) connected before opening, Yshaped; (1) open separately.

129. M. frontobuccalis lateralis (0hy2): (0) present; (1) absent.

130. M. craniohypopharyngealis (0hy3): (0) present; (1) absent.

131. M. postmentoloralis (0hy6): (0) present; (1) absent.

132. M. praementosalivaris posterior (0hy8): (0) absent; (1) present.

133. M. lorosalivarialis (0hy11): (0) present; (1) absent.

134. 0hy12: (0) present; (1) absent.

135. M. frontobuccalis posterior (0bu3): (0) present; (1) absent.

136. M. tentoriobuccalis lateralis (0bu4): (0) absent; (1) present.

137. 0bu5: (0) present; (1) absent.

138. 141. M. tentoriobuccalis posterior (0bu6): (0) present; (1) absent.

139. Origin of M. tentoriobuccalis posterior 0bu6 (M.50): (0) corpotentorium or posterior tentorial body, (1) anterior tentorial arms or anterior tentorial body. 